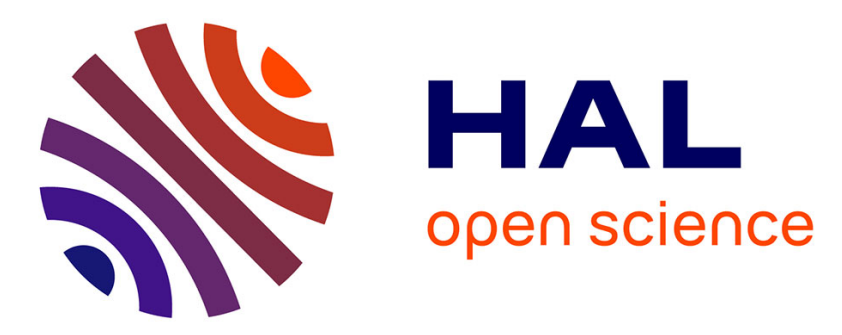

\title{
Controlled crystallization of hierarchical monoliths composed of nano-zeolites
}

Kassem Moukahhal, Nghia Huu Le, Magali Bonne, Joumana Toufaily, Tayssir Hamieh, T Jean Daou, Bénédicte Lebeau

\section{- To cite this version:}

Kassem Moukahhal, Nghia Huu Le, Magali Bonne, Joumana Toufaily, Tayssir Hamieh, et al.. Controlled crystallization of hierarchical monoliths composed of nano-zeolites. Crystal Growth \& Design, 2020. hal-03060060

\section{HAL Id: hal-03060060 https://hal.science/hal-03060060}

Submitted on 13 Dec 2020

HAL is a multi-disciplinary open access archive for the deposit and dissemination of scientific research documents, whether they are published or not. The documents may come from teaching and research institutions in France or abroad, or from public or private research centers.
L'archive ouverte pluridisciplinaire HAL, est destinée au dépôt et à la diffusion de documents scientifiques de niveau recherche, publiés ou non, émanant des établissements d'enseignement et de recherche français ou étrangers, des laboratoires publics ou privés. 


\title{
Controlled crystallization of hierarchical monoliths
}

\section{composed of nano-zeolites}

\author{
Kassem Moukahhal 1,2,3, Nghia Huu Le ${ }^{1,2}$, Magali Bonne ${ }^{1,2}$, Joumana Toufaily ${ }^{3}$, Tayssir Hamieh ${ }^{3}$, \\ T. Jean Daou ${ }^{1,2 *}$ Bénédicte Lebeau ${ }^{1,2 *}$
}

1) Université de Haute Alsace (UHA), CNRS, IS2M UMR 7361, F-68100 Mulhouse, France

2) Université de Strasbourg, F-67000 Strasbourg, France

3) Laboratory of Materials, Catalysis, Environment and Analytical Methods Faculty of Sciences, Section I, Lebanese University Campus Rafic Hariri, Hadath, Lebanon

KEYWORDS. Zeolite monolith, hierarchical zeolite, pseudomorphic transformation, ZSM-5, shaping, nanosheets.

ABSTRACT. Micro/macroporous and meso/macroporous amorphous silica monoliths have been prepared and transformed into ZSM-5 nanosheets zeolitic macroporous monoliths. The hierarchized zeolite monoliths have been optimized in term of crystallinity rate by varying durations and temperatures of hydrothermal treatments. Fully crystallized ZSM-5 nanosheets monoliths were obtained after a combination of two consecutive hydrothermal treatments at 150 ${ }^{\circ} \mathrm{C}$ for 5 days with stirring and at $120{ }^{\circ} \mathrm{C}$ for 1 day under static conditions. A ZSM-5 nanosheets 
monolith similar in shape and dimensions to the original amorphous micro/macroporous silica monolith was obtained, but a partial reduction in size has been observed for the ZSM-5 nanosheets monolith obtained from the amorphous meso/macroporous silica monolith due to a partial dissolution. Results showed that the macropores of the parent silica monoliths were preserved after the transformation with similar diameter sizes but with a wider pores size distributions and additional mesopores systems thanks to the nanosheets morphology.

\section{INTRODUCTION}

Zeolites are crystalline aluminosilicate materials commonly used in applications related to adsorption, separation and catalysis ${ }^{1-4}$. Zeolites are widely used as solid catalysts in the (petro)chemical industry thanks to their high intrinsic acidity and thermal stability ${ }^{5-11}$. The micropores network in zeolites is very well controlled in terms of size and topology. However, the micropore dimensions in major lower than $1 \mathrm{~nm}$ is a limit for molecules with kinetic diameter larger than pore entrance. Moreover, the size of zeolite crystals that is in the few micron range is limiting for diffusion within the microporous network and thus for the accessibility to active sites.

Consequently, to enlarge the application field of zeolites in catalysis to voluminous molecules it is necessary to favor both their accessibility to the active sites and their diffusion within the solid porosity ${ }^{12,13}$. To reach these goals several investigations have been oriented not only on the preparation of zeolites with larger pores and nanosized zeolites ${ }^{14-21}$, but also on the synthesis of zeolites with hierarchized porosity. Such hierarchized zeolites possess at least two grades of pore systems including mesopores and/or macropores with the intrinsic zeolite micropores ${ }^{8,22-28}$. Several strategies have emerged to produce hierarchized zeolites ${ }^{29,30}$ such as framework 
desilication or dealumination ${ }^{31}$, hard-templating method ${ }^{32-34}$, soft templating method ${ }^{35-40}$ and dual templating route with bifunctional surfactants ${ }^{41-44}$. These latter are composed of long-chain alkyl groups and polar quaternary ammonium groups separated by a short alkyl spacer: the quaternary ammonium groups can generate the zeolite structure, while hydrophobic alkyl chains block the zeolitic framework growth along one direction and can assemble into a mesoscale micellar structure to create mesoporosity. This approach is quite interesting because the nature of the bifunctional agent and the synthesis conditions allow controlling the morphology (e.g. nanosheet, nanosponge) and the texture of the produced zeolitic materials ${ }^{41-45}$.

The micron-size of zeolites crystals $(0.5-25 \mu \mathrm{m})$ is also a limit for their use in some processes such as continuous fluid flow ones that require shaping into larger particles. Zeolites must be therefore shaped at the macroscopic scale with high mechanical resistance. Several methods have been developed for shaping zeolite particles. In most processes, the zeolite particles are shaped as extruded. Extrusion methods involve several steps usually including/following grinding, sieving, binder additions and extrusion. Although these extruded particles exhibit high mechanical resistance, they usually present an uncontrolled secondary porosity and require several stages of development. In addition, the use of inorganic binders (e.g. alumina, clays) and organic binders (e.g. carboxymethylcellulose) can strongly affect the catalytic and adsorption properties of the material if they are used in a large amount. As a result, many efforts have been brought on the implementation of methods for shaping zeolite particles without the addition of binders or by using small amounts of binders (5 wt.\%). These methods are mainly based on the compaction of zeolitic powders, or the use of a mixer, introduction of sacrificial macrotemplates (e.g. resin), the hydrothermal transformation of dense aluminosilicate gels and pseudomorphic transformation of shaped amorphous silica materials ${ }^{46-50}$. 
Pseudomorphism that consists in transforming one material to another one without modifying the initial morphology is particularly interesting for materials shaping since it is a one-step and binderless method ${ }^{51}$. It involves the dissolution of the parent material with the simultaneous precipitation or crystallization of the targeted material without any change of the external shape. This concept has been used by Galarneau's group for the synthesis of beads of MCM-41 and MCM48 types mesoporous silica-based materials with micron-size $(5-800 \mu \mathrm{m})$ from amorphous silica beads of the same size ${ }^{52,53}$. More recently, this method was extended to the synthesis of zeolite beads (from $10 \mu \mathrm{m}$ to $1 \mathrm{~mm}$ diameter) of type SOD, LTA, FAU-X, and cylindrical zeolite monoliths (of 3-5 cm in length) of type LTA, FAU-X, from amorphous mesoporous silica beads and amorphous meso/macroporous silica monoliths, respectively ${ }^{54,55}$. The resulting LTA monoliths showed high adsorption capacities for decontamination radioactive aqueous effluents in continuous flow thanks to their fast ion-exchange kinetics ${ }^{56}$. Our group has recently described the one-step synthesis of ZSM-5 nanosheets beads with different sizes by using the pseudomorphism concept ${ }^{57}$. Here, we describe the pseudomorphic transformation of two types of amorphous silica monoliths having bimodal micro/macro and meso/macro porosity, into ZSM-5 nanosheets monoliths.

The amorphous silica monoliths with sponge-like continuous macroporous network have been prepared by the Nakanishi's method ${ }^{58,59}$. The resulting macroporous monoliths present an interparticular microporosity between silica nanoparticles constituting the silica skeleton. To release the porosity a thermal treatment is usually applied but results in the partial destruction of the macroscopic shape ${ }^{56}$. Therefore, a post-synthesis treatment with a base is realized to create mesoporosity that confers to the monoliths the mechanical stability necessary to stand the thermal treatment applied for the organic polymer removal ${ }^{59-62}$. This post-synthesis treatment consists in 
immersing monoliths in a basic solution to generate disordered mesopores in the silica skeleton of monolith. This treatment involves the Ostwald ripening within the silica network to create interparticular mesoporosity and improve the silica condensation. Temperature of the treatment and basicity of the solution can be varied to control the mesopores size ${ }^{61,63}$. In the present work, meso/macroporous amorphous silica monoliths have been synthesized by a post-treatment with a base but the synthesis of silica monoliths was also optimized to obtain for the first time mechanically stable micro/macroporous monoliths. The transformation of porous amorphous silica monoliths into hierarchized ZSM-5 zeolite monoliths was realized by following the protocol developed for the ZSM-5 nanosheets beads ${ }^{57}$.

\section{EXPERIMENTAL SECTION}

Synthesis of macroporous silica monoliths with microporosity. The macroporous silica monoliths with microporosity were prepared by optimizing the protocol described by Galarneau's group $^{60,62}$, which was inspired by the original work of Nakanishi ${ }^{58,59}$. In a first step, a very accurate amount of tetraethoxysilane (TEOS, Sigma-Aldrich) (12.62 g) was weighted with the aid of a plastic syringe and kept in a refrigerator at $0{ }^{\circ} \mathrm{C}$ for $1 \mathrm{~h}$. A precise amount $(1.690 \mathrm{~g})$ of $35 \mathrm{kDa}$ poly(ethylene oxide) (PEO, Sigma-Aldrich)) was weighted and introduced in a $50 \mathrm{~mL}$ beaker containing a mixture of precisely measured $16 \mathrm{~mL}$ of distilled water and $1 \mathrm{~mL}$ of nitric acid. The beaker was placed in a laboratory glass crystallizer well surrounded by ice (constant bath temperature of $0{ }^{\circ} \mathrm{C}$ ) and the mixture was stirred for 30 min under magnetic stirring at $400-500$ rpm until total polymer dissolution. In a second step, the cold TEOS $\left(0{ }^{\circ} \mathrm{C}\right)$ was directly added from the syringe to the polymer solution in the beaker under stirring. The stirring was maintained to obtain a homogeneous gel. This stirring step is important for optimizing the mechanical stability of the resulting silica monoliths. Two hydrodynamic regimes of this ripening phase corresponding 
to two different stirring ways were applied: (regime A) the solution was let for only $30 \mathrm{~min}$ at 400 rpm or (regime B) the solution was let for $30 \mathrm{~min}$ at $250 \mathrm{rpm}$ and then for $30 \mathrm{~min}$ at $400 \mathrm{rpm}$. The final molar composition of the gel is: $1 \mathrm{SiO}_{2}: 4 \mathrm{EtOH}$ : 0.63EO: $0.25 \mathrm{HNO}_{3}: 14.8 \mathrm{H}_{2} \mathrm{O}(\mathrm{EtOH}$ stands for ethanol obtained from the hydrolysis of TEOS; EO stands for ethylene oxide unit). In a third step, 12 poly(vinyl chloride) (PVC) tubes $(8 \mathrm{~mm}$ diameter and $40 \mathrm{~mm}$ length) stored in the refrigerator at $0{ }^{\circ} \mathrm{C}$ were filled with the cold TEOS/PEO/ $\mathrm{HNO}_{3} / \mathrm{H}_{2} \mathrm{O}$ mixture. The tubes were then closed, sealed with Parafilm $\mathrm{M} \circledast$ and put in an oven at $40{ }^{\circ} \mathrm{C}$ for $72 \mathrm{~h}$. In a fourth step, monoliths were removed from the PVC tubes and washed in $1 \mathrm{~L}$ of distilled water at room temperature. Distilled water was renewed every $2 \mathrm{~h}$ (about 10 times) until a neutral $\mathrm{pH}$ was reached. In a last step, monoliths were dried at room temperature. The monoliths were weighted every $12 \mathrm{~h}$ to follow the loss of moisture until reaching a constant weight. This drying step (lasting about 6 days) combined with sample weighting is necessary to obtain mechanically stable monoliths. It is noteworthy that drying was also tested at 40 and $60^{\circ} \mathrm{C}$ in an oven but it resulted in cracks in the monoliths.

Monoliths were calcined under air at $550{ }^{\circ} \mathrm{C}$ for $6 \mathrm{~h}$ in order to liberate the macropores occluded by PEO. The heating rate of $0.7^{\circ} \mathrm{C} / \mathrm{min}$ from 20 to $550{ }^{\circ} \mathrm{C}$ is fast enough to warrant the mechanical strength of the resulting silica monoliths. The obtained monoliths of $4 \mathrm{~mm}$ diameter and $40 \mathrm{~mm}$ length were stored in a vacuum desiccator for preservation. The stable parent micro/macroporous silica monoliths will be noted "M".

Synthesis of macroporous silica monoliths with disordered mesoporosity. The macroporous silica monoliths with disordered mesoporosity were prepared by applying a post-synthesis treatment in basic medium to the wet silica monoliths obtained after the washing step (fourth step) according the procedure described above $\mathrm{s}^{59,61}$. The wet silica monoliths were immersed in $70 \mathrm{~mL}$ 
aqueous ammonia $\left(\mathrm{NH}_{4} \mathrm{OH}, 1 \mathrm{M}\right)$ in a glass flask and left in an oven at $80{ }^{\circ} \mathrm{C}$ for $24 \mathrm{~h}$. The resulting monoliths were then washed in $1 \mathrm{~L}$ distilled water bath at room temperature. Distilled water was renewed every $2 \mathrm{~h}$ (about 8 times) until a neutral $\mathrm{pH}$ was reached. The monoliths were dried, calcined and conserved by following the last steps described above for micro/macroporous silica monoliths. The parent meso/macroporous silica monolith will be noted "N".

Synthesis of ZSM-5 nanosheets monoliths. For the pseudomorphic transformation of the micro/macroporous silica monolith M into ZSM-5 nanosheets monolith, the protocol for ZSM-5 nanosheets beads synthesis recently developed was followed ${ }^{57}$. The bifunctional organic surfactant: $\left[\mathrm{C}_{22} \mathrm{H}_{45}-\mathrm{N}^{+}\left(\mathrm{CH}_{3}\right)_{2}-\right.$ $\left.\mathrm{C}_{6} \mathrm{H}_{12}-\mathrm{N}^{+}\left(\mathrm{CH}_{3}\right)_{2}-\mathrm{C}_{6} \mathrm{H}_{13}\right] \mathrm{Br}_{2}$ named $\mathrm{C}_{22-6-6}$, was prepared according to the two steps procedure described in the literature ${ }^{41}$. The synthesis protocol is described for a calcined silica monolith with length of $26 \mathrm{~mm}$ and diameter of $4 \mathrm{~mm}\left(256 \mathrm{mg}\right.$ of $\mathrm{SiO}_{2}$ ). In a beaker, $0.10 \mathrm{~g}$ sodium hydroxide (Carlo Erba, 99\%) and $0.03 \mathrm{~g}$ $\mathrm{Al}_{2}\left(\mathrm{SO}_{4}\right)_{3} .18 \mathrm{H}_{2} \mathrm{O}$ (Rectaptur, 99\%) were dissolved in $3 \mathrm{~g}$ of distilled water, then $0.35 \mathrm{~g} \mathrm{C}_{22-6-6}$ and $0.08 \mathrm{~g}$ sulfuric acid (Sigma-Aldrich, 96\%) were added under stirring. The resulting solution was poured onto the silica monolith previously placed into a $45 \mathrm{~mL}$ Teflon®-lined stainless steel autoclave to set a molar composition of: $1 \mathrm{SiO}_{2}: 0.3 \mathrm{Na}_{2} \mathrm{O}: 0.01 \mathrm{Al}_{2} \mathrm{O}_{3}: 0.18 \mathrm{H}_{2} \mathrm{SO}_{4}: 0.1 \mathrm{C}_{22-6-6}: 40 \mathrm{H}_{2} \mathrm{O}$. The mixture was left at $60{ }^{\circ} \mathrm{C}$ during $2 \mathrm{~h}$ without stirring and then put in an oven with rotating shaking $(30 \mathrm{rpm})$ at $150{ }^{\circ} \mathrm{C}$ for 5 days and next in static mode at $120{ }^{\circ} \mathrm{C}$ for 1,2 or 5 days. After cooling down, the monoliths were recovered and immersed in a distilled water bath: water was renewed every 15 min until a neutral $\mathrm{pH}$ was reached. The monoliths were then dried overnight at $80{ }^{\circ} \mathrm{C}$ and calcined in a furnace at $550{ }^{\circ} \mathrm{C}$ for $8 \mathrm{~h}$ to remove the $\mathrm{C}_{22-}$ 6-6 surfactant. The resulting monoliths are named M-x-y, with $\mathrm{x}$ the number of hydrothermal treatment days at $150{ }^{\circ} \mathrm{C}$ and $\mathrm{y}$ the number of hydrothermal treatment days at $120^{\circ} \mathrm{C}$.

The optimal conditions obtained for the pseudomorphic transformation of the monolith $\mathrm{M}$ into a ZSM-5 nanosheet monolith have been applied to the meso/macroporous silica monolith $\mathrm{N}$ with 27 $\mathrm{mm}$ length and $5 \mathrm{~mm}$ of diameter $\left(175 \mathrm{mg}\right.$ of $\left.\mathrm{SiO}_{2}\right)$ by adjusting the reagents amount. The obtained 
monolith after transformation is named $\mathrm{N}-\mathrm{x}-\mathrm{y}(\mathrm{x}=$ number of hydrothermal treatment days at 150 ${ }^{\circ} \mathrm{C} ; \mathrm{y}=$ number of hydrothermal treatment days at $120{ }^{\circ} \mathrm{C}$ ).

Characterizations. X-ray diffraction patterns were recorded in the range $3<2 \theta<50^{\circ}$ on a STOE STADI$\mathrm{P}$ diffractometer with $\mathrm{Cu}-\mathrm{K}_{\alpha 1}$ radiation $(\lambda=0.15406 \mathrm{~nm})$. The morphology of the synthesized materials was investigated using a transmission electron microscope (TEM) JEOL model ARM-200F under an acceleration voltage of $200 \mathrm{kV}$ and a scanning electron microscope (SEM) Philips model XL30 FEG under an acceleration voltage of $7 \mathrm{kV}$. Nitrogen sorption isotherms were recorded at $-196{ }^{\circ} \mathrm{C}$ using a Micromeritics model ASAP 2420 analyzer after out-gassing samples under vacuum for $1 \mathrm{~h}$ at $90{ }^{\circ} \mathrm{C}$ then overnight at $300{ }^{\circ} \mathrm{C}$. Specific surface areas $\left(\mathrm{S}_{\mathrm{BET}}\right)$ were calculated by using the BET method in the selected relative pressure ranges $\left(0.02<\mathrm{p} / \mathrm{p}^{\circ}<0.1\right.$ for almost the analyzed samples and $0.05<\mathrm{p} / \mathrm{p}^{\circ}<0.4$ for the parent silica monolith $\mathrm{N})$. The given total pore volumes $\left(\mathrm{V}_{\text {tot }}\right)$ were derived from the $\mathrm{N}_{2}$ adsorbed volumes at $\mathrm{p} / \mathrm{p}^{\circ}=0.99$. The pore size distributions were deduced from the adsorption branches of the isotherms by applying the Density Functional Theory (DFT), which is reliable over the total range of micro- and mesopores ${ }^{64,65}$. The microporous volumes $\left(\mathrm{V}_{\text {micro }}\right)$ of parent monoliths and ZSM-5 nanosheets monoliths were determined from the cumulative pore volume. The amount of bifunctional surfactant present in ZSM5 monoliths was evaluated by thermogravimetric analyses performed on a METTLER TOLEDO TG/DSC STARe system from 20 to $800{ }^{\circ} \mathrm{C}$ under air (heating rate of $5{ }^{\circ} \mathrm{C} / \mathrm{min}$ ). In order to determine the Si/Al molar ratio, the $\mathrm{Si}$ and $\mathrm{Al}$ contents of the different materials were determined by ICP-OES (Inductively Coupled Plasma Optical Emission Spectroscopy) on a Thermo-Model 6300DUO spectrometer. The samples were dissolved for at least $12 \mathrm{~h}$ under stirring in $\mathrm{HF}(0.025$ gram of test sample $+2 \mathrm{~mL}$ of $48.9 \% \mathrm{HF})$ at roomtemperature, diluted to $50 \mathrm{~mL}$ and filtered at $0.45 \mu \mathrm{m}$ before analysis. Mercury intrusion experiments were performed on monoliths using a Micromeritics model AutoPore IV. Monoliths were preliminary outgassed one night at $150{ }^{\circ} \mathrm{C}$ under vacuum. 


\section{RESULTS AND DISCUSSION}

Parent amorphous silica monoliths. In an effort to synthesize stable macroporous silica monoliths with only microporosity inside the silica skeleton, the hydrodynamic regime of ripening phase with stirring has been optimized. Two regimes corresponding to two different stirring ways have been applied to the synthesis of monolith M. It is noteworthy that for each protocol at least 3 monoliths have been synthesized to check the reproducibility. After thermal treatment at $550{ }^{\circ} \mathrm{C}$ to remove the PEO polymer from monoliths, some cracks were observed for those synthesized by stirring the synthesis gel for only $30 \mathrm{~min}$ at a vigorously magnetic stirring of $400 \mathrm{rpm}$ (regime A) (Fig. 1a). On the other hand, monoliths synthesized by stirring the synthesis gel for $30 \mathrm{~min}$ at a magnetic stirring of $250 \mathrm{rpm}$ and then for $30 \mathrm{~min}$ at a magnetic stirring of $400 \mathrm{rpm}$ (regime B) are intact (Fig. 1b). There is a gain of stability of the silica monoliths when the regime B is used.
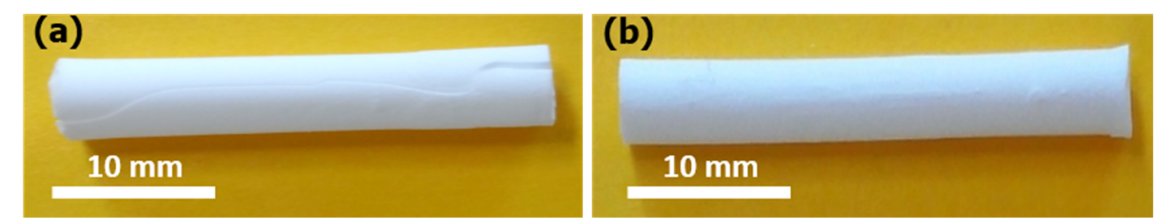

Figure 1. Macroscopic images of the calcined monoliths prepared by stirring the synthesis gel (a) for only $30 \mathrm{~min}$ at a vigorously magnetic stirring of $400 \mathrm{rpm}$, and (b) for $30 \mathrm{~min}$ at a magnetic stirring of $250 \mathrm{rpm}$ and then for $30 \mathrm{~min}$ more at a magnetic stirring of $400 \mathrm{rpm}$ 


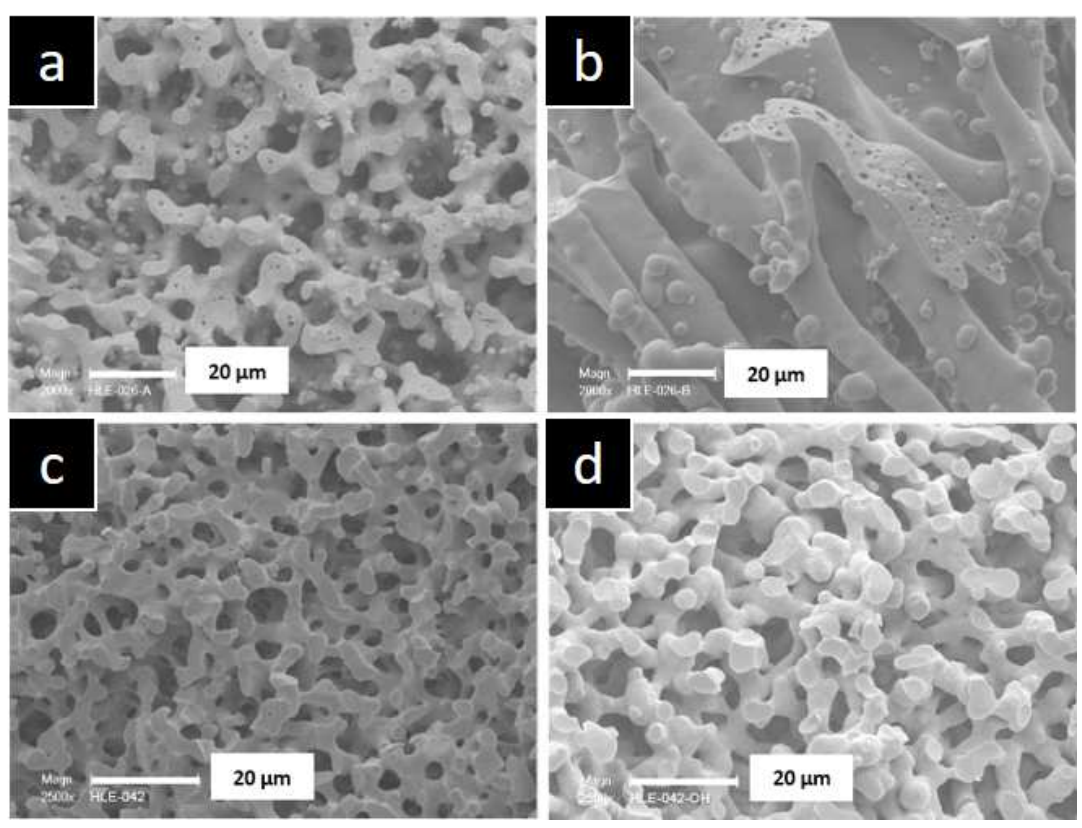

Figure 2. SEM images of the calcined monoliths prepared by stirring the synthesis gel (a) and (b) for only $30 \mathrm{~min}$ at a vigorously magnetic stirring of $400 \mathrm{rpm}$, (c) for $30 \mathrm{~min}$ at a magnetic stirring of $250 \mathrm{rpm}$ and then for $30 \mathrm{~min}$ more at a magnetic stirring of $400 \mathrm{rpm}$ (Parent silica monolith $\mathrm{M}$ ), and (d) prepared by applying the treatment in basic medium (Parent silica monolith $\mathrm{N}$ )

The SEM images (Fig. 2a, 2b, 2c) show the morphology of the two synthesized monoliths mentioned above. For the monolith prepared under only 30 min of vigorous stirring (400 rpm) a macroporous silica skeleton with sponge-like morphology coexisting with several spherical particles and holes inside the silica walls, was observed (Fig. 2a). The morphology of this monolith is not homogeneous as confirmed by the micrograph displayed in Fig. $2 b$ that shows another longitudinal area of the monolith: absence of the sponge-like morphology, presence of larger spherical silica particles and several holes in the silica walls. In the case of the monolith synthesized by using the stirring regime B only a macroporous silica skeleton with sponge-like morphology without defect inside was observed (Fig. 2c). This monolith sample exhibits a homogeneous 
interconnected macropores network with average pores size of $3 \mu \mathrm{m}$ and a silica skeleton of average thickness of $2-3 \mu \mathrm{m}$. Thanks to these differences of the internal structure, this monolith (M) exhibited a better mechanical stability after PEO removal upon thermal treatment at $550{ }^{\circ} \mathrm{C}$. After the basic treatment a sponge-like morphology with well-defined continuous macroporous network similar to the one of monolith $\mathrm{M}$ was observed for monolith $\mathrm{N}$ (Fig. 2d).

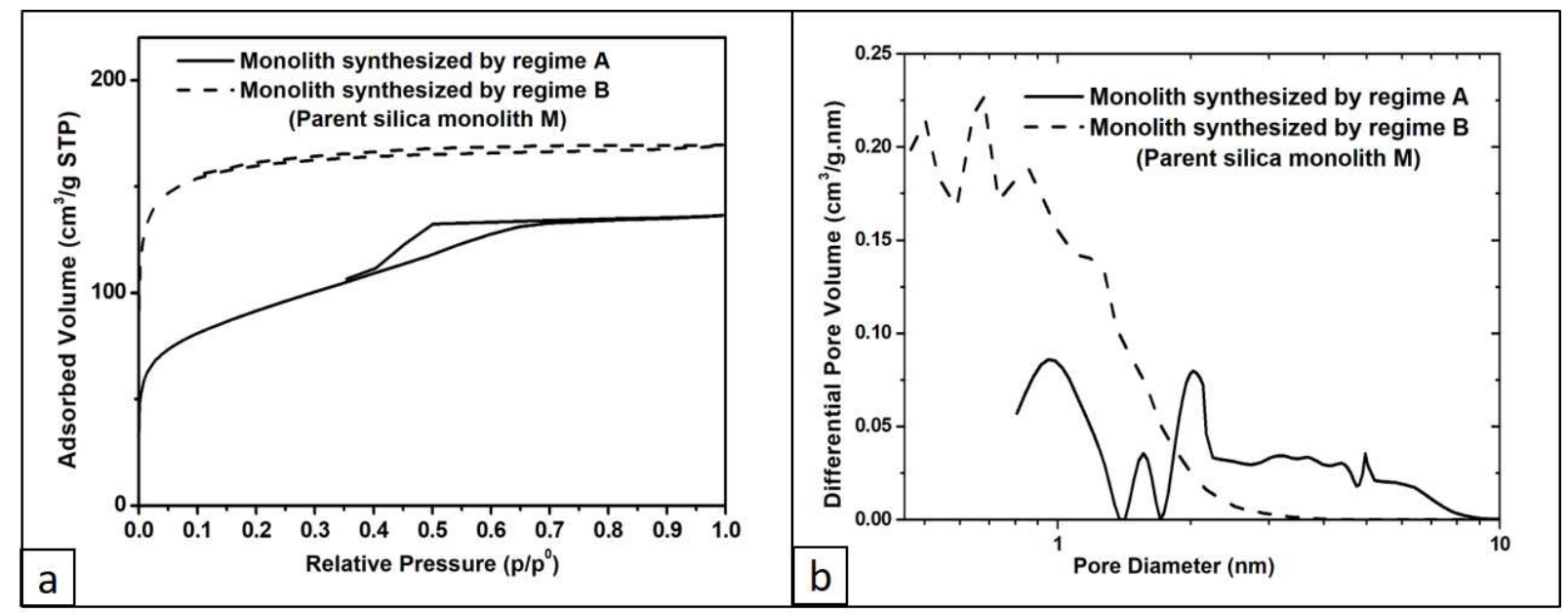

Figure 3. (a) $\mathrm{N}_{2}$ adsorption-desorption isotherms at $77 \mathrm{~K}$ and (b) pore size distributions of the calcined monoliths prepared by the stirring regime A (only 30 min at a vigorously magnetic stirring of $400 \mathrm{rpm}$ ), the stirring regime $\mathrm{B}$ (for $30 \mathrm{~min}$ at a magnetic stirring of $250 \mathrm{rpm}$ and then for $30 \mathrm{~min}$ more at a magnetic stirring of $400 \mathrm{rpm}$ - Parent silica monolith M)

The nitrogen adsorption/desorption isotherms of the two micro/macroporous monoliths obtained by two stirring regimes indicate the difference in their textural properties (Fig. 3). The one of the monolith synthesized by stirring regime B is type I (according to the IUPAC classifications of $\mathrm{N}_{2}$ sorption isotherms) indicating the presence of micropores. Meanwhile, the isotherm of the monolith 
synthesized by stirring regime $\mathrm{A}$ is a mixture of type I (microporosity) and type IV with a $\mathrm{H} 2 \mathrm{~b}$ hysteresis (mesoporosity with pores partially blocking due to the pore topology). This means that this monolith has both micropores and mesopores in silica skeleton. The presence of mesoporosity is due to the formation of silica nanoparticles with brad particle size distribution and/or a heterogeneous agglomeration of silica nanoparticles during gelification process. A more homogeneous agglomeration of silica nanoparticles has occurred in the case of the monoliths synthesized by stirring regime B. The pore size distributions confirm the existence of mesoporosity in the monoliths synthesized with stirring regime A.

These results confirm that the hydrodynamic regime of the ripening phase induced by the stirring during the silica monolith synthesis is an important factor to be controlled in order to obtain mechanically stable micro-macroporous monoliths. After the simultaneous sol-gel transition/spinodal decomposition the obtained monolith is macro and microporous. ${ }^{58}$ Walls delimiting the continuous macroporous network are constituted of aggregated silica nanoparticles, which create interparticular microporosity. The magnetic stirring applied during the ripening phase can create a vortex at high speed, which generates heterogeneities in the liquid synthesis medium. It is assumed that these heterogeneities generate nanoparticles more polydisperse in size and thus result in a broad pore size distribution going from micro- to mesopores as observed in Fig $3 \mathrm{~b}$.

It should be noted that the drying and calcination steps have to be carefully respected to avoid any perturbation from environment conditions (controlled temperature and relative humidity, no air flow). Mechanically stable micro/macroporous silica monoliths M (Regime B) were used for the synthesis of the ZSM-5 nanosheets monoliths by pseudomorphism. 
As expected, the $\mathrm{N}_{2}$ adsorption/desorption isotherm of monolith $\mathrm{N}$ is type IV characteristics of mesoporous solid (Fig. S1). Textural characteristics determined from the $\mathrm{N}_{2}$ adsorption/desorption isotherms of monoliths and $\mathrm{M}$ and $\mathrm{N}$ are presented in Table 1. The pore size distributions determined on nitrogen adsorption branches confirm that for the monolith $\mathrm{M}$ the average micropore size is $<1 \mathrm{~nm}$, and that for the monolith $\mathrm{N}$ the average micropore size is of $1.5 \mathrm{~nm}$ and the average mesopore size is of $14 \mathrm{~nm}$. The microporous volume is very low for monolith $\mathrm{N}$ confirming its predominant mesoporosity. The post-treatment with $\mathrm{NH}_{4} \mathrm{OH}$ realized in a second step has created large mesopores in the monoliths walls by dissolution/re-precipitation of silica (Ostwald ripening): the silica network of monolith $\mathrm{M}$ rearranges to form silica nanoparticles that aggregate and form mesopores in the interparticles space ${ }^{60,62}$. It is noteworthy that this step is controlled by the temperature, the amount of base and the treatment duration, resulting in mesopores regular in size, which can be controlled from 5 to over $50 \mathrm{~nm}^{61}$. As a consequence, micropores almost disappear and mesoporosity become predominant. A decrease of specific surface is thus observed from 609 $\mathrm{m}^{2} / \mathrm{g}$ for the monolith $\mathrm{M}$ down to $249 \mathrm{~m}^{2} / \mathrm{g}$ for the monolith $\mathrm{N}$. Both monoliths $\mathrm{M}$ and $\mathrm{N}$ were characterized by mercury intrusion. The mercury intrusion-extrusion curves and pore size distributions are displayed in Fig. 4. Both monoliths $\mathrm{M}$ and $\mathrm{N}$ are characterized by narrow distributed macropores centered at 4.5 and $8 \mu \mathrm{m}$, respectively. The appearance of a second step at the position of around $14 \mathrm{~nm}$ on the mercury intrusion-extrusion curve of monolith $\mathrm{N}$ in comparison with the curve of monolith $\mathrm{M}$ (only one step at $4.5 \mu \mathrm{m}$ ) is noted and consistent with $\mathrm{N}_{2}$ adsorption/desorption results. The monoliths $\mathrm{M}$ and $\mathrm{N}$ have a macroporous volume of 0.87 and $1.40 \mathrm{~mL} / \mathrm{g}$, respectively. 


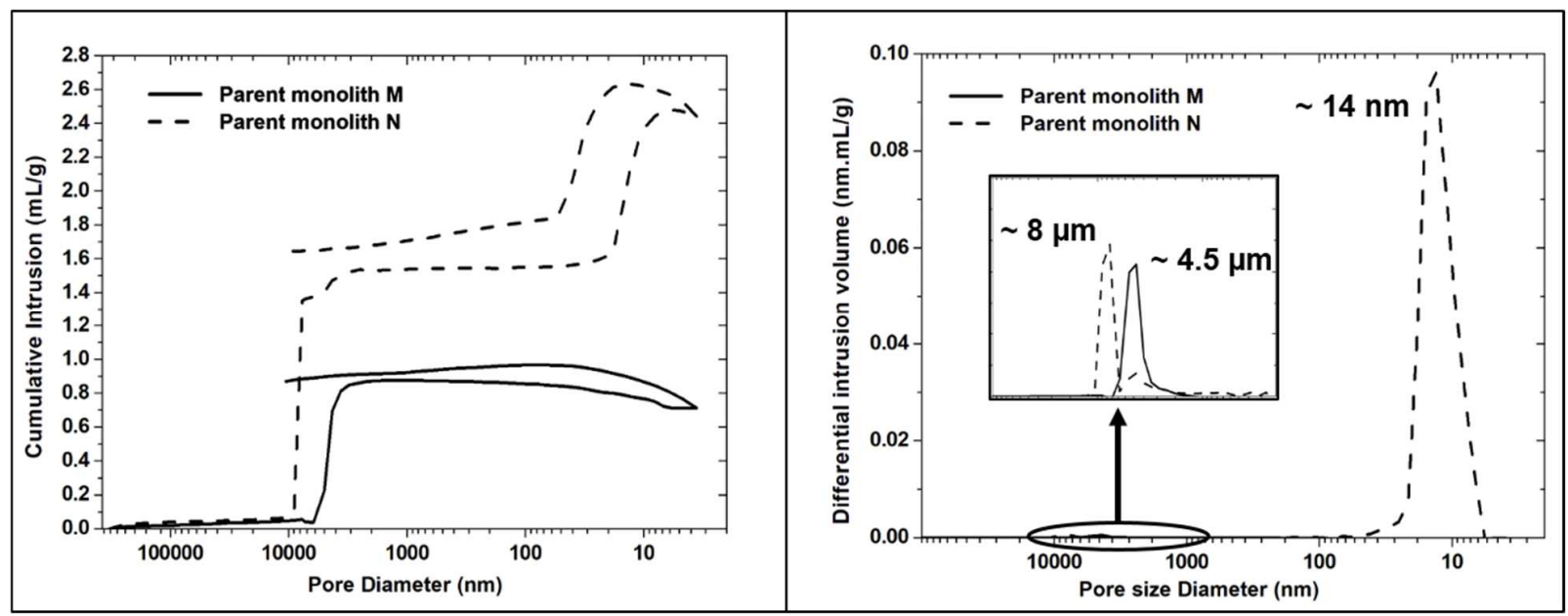

Figure 4. Mercury intrusion-extrusion curves (left) and pore size distributions (right) of the parent silica monoliths $\mathrm{M}$ and $\mathrm{N}$

Table 1. Textural properties of the two parent silica monoliths $\mathrm{M}$ and $\mathrm{N}$

\begin{tabular}{|c|c|c|c|c|c|c|c|c|}
\hline & $\begin{array}{c}\mathrm{S}_{\mathrm{BET}} \\
\left(\mathrm{m}^{2} / \mathrm{g}\right)\end{array}$ & $\begin{array}{c}\mathrm{V}_{\mathrm{tot}^{\mathrm{a}}} \\
\left(\mathrm{cm}^{3} / \mathrm{g}\right)\end{array}$ & $\begin{array}{c}\mathrm{V}_{\text {micro }} \\
\left(\mathrm{cm}^{3} / \mathrm{g}\right)\end{array}$ & $\begin{array}{l}\mathrm{V}_{\text {meso }}{ }^{\mathrm{a}} \\
\left(\mathrm{cm}^{3} / \mathrm{g}\right)\end{array}$ & $\begin{array}{l}\mathrm{V}_{\text {macro }} \mathrm{b} \\
(\mathrm{mL} / \mathrm{g})\end{array}$ & $\begin{array}{c}\mathrm{D}_{\text {micro }}{ }^{\mathrm{c}} \\
(\mathrm{nm})\end{array}$ & $\begin{array}{l}\mathrm{D}_{\text {meso }}{ }^{\mathrm{d}} \\
(\mathrm{nm})\end{array}$ & $\begin{array}{r}D_{\text {macro }}{ }^{e} \\
(\mu \mathrm{m})\end{array}$ \\
\hline Monolith M & 609 & 0.25 & 0.25 & 0.00 & 0.87 & $0.5-$ & - & $3-6$ \\
\hline
\end{tabular}

$\begin{array}{llllllll}\text { Monolith N } & 249 & 1.21 & 0.03 & 1.18 & 1.40 & 1.2- & 12-\end{array}$

${ }^{a}$ Mesoporous volume: $V_{\text {meso }}=V_{\text {tot }}-V_{\text {mircro total }}$

${ }^{b}$ Macroporous volume determined by using mercury intrusion branch

${ }^{c, d}$ Micropores and mesopores diameters determined from the pore size distribution 
${ }^{e}$ Macropores diameter determined from the pore size distribution deduced from the mercury intrusion branch

ZSM-5 nanosheets monoliths synthesized from macro/microporous silica monoliths. The crystallinity of ZSM-5 nanosheets monoliths synthesized by pseudomorphism from the micro/macroporous silica monolith M was analyzed by X-ray diffraction (Fig. 5). The XRD peaks were indexed and are consistent with pure MFI-type zeolite. The presence of only h01 reflections indicates the growth inhibition along the $b$-axis as expected with the use of $C_{22-6-6}$ bifunctional agent, and confirms the formation of ZSM-5 nanosheets. No halo between 20 and $30^{\circ} 2 \theta$ characteristic of amorphous silica was detected indicating the total dissolution of silica walls and thus the well crystallization of ZSM-5 nanosheets.

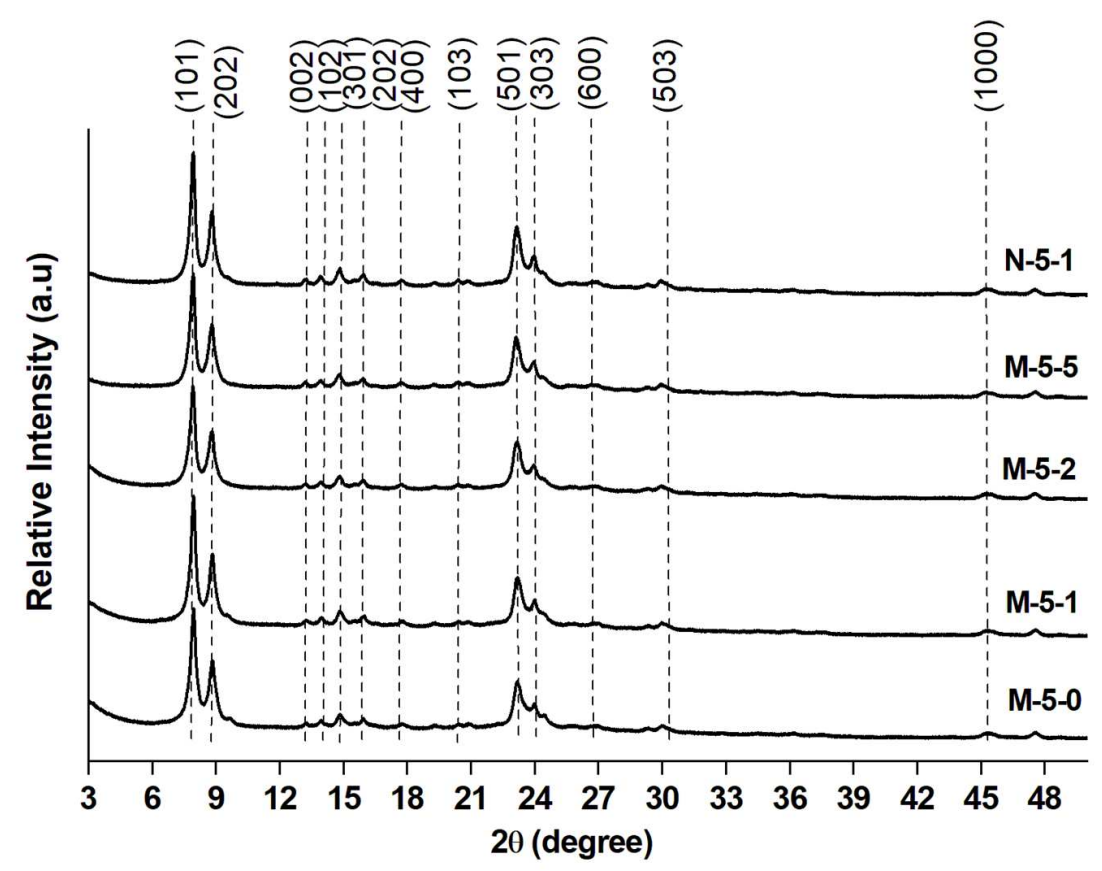

Figure 5. XRD patterns of the ZSM-5 nanosheets monoliths obtained after different durations of the hydrothermal treatment at $120^{\circ} \mathrm{C}$ 
Fig. 6 displays the photographs of the parent silica monolith M and of the ZSM-5 nanosheets monolith M-5-1. The macroscopic shape of the parent amorphous silica monolith was conserved after pseudomorphic transformation. The resulting ZSM-5 nanosheets monolith have the same length of the parent monolith M but the external surface of the monolith was slightly eroded during the synthesis of the ZSM-5 nanosheet monolith M-5-1. It is assumed that a part of the silica monolith was dissolved. Although the method was slightly different, Ocampo et al have noticed a dissolution of the glass support when zeolitization was performed ${ }^{67}$. The yellowish color of ZSM5 nanosheets monoliths was attributed to the $\mathrm{C}_{22-6-6}$ bifunctional agent since after calcination at 550 ${ }^{\circ} \mathrm{C}$ the monolith was recovered white with its initial shape (Fig. S2a).
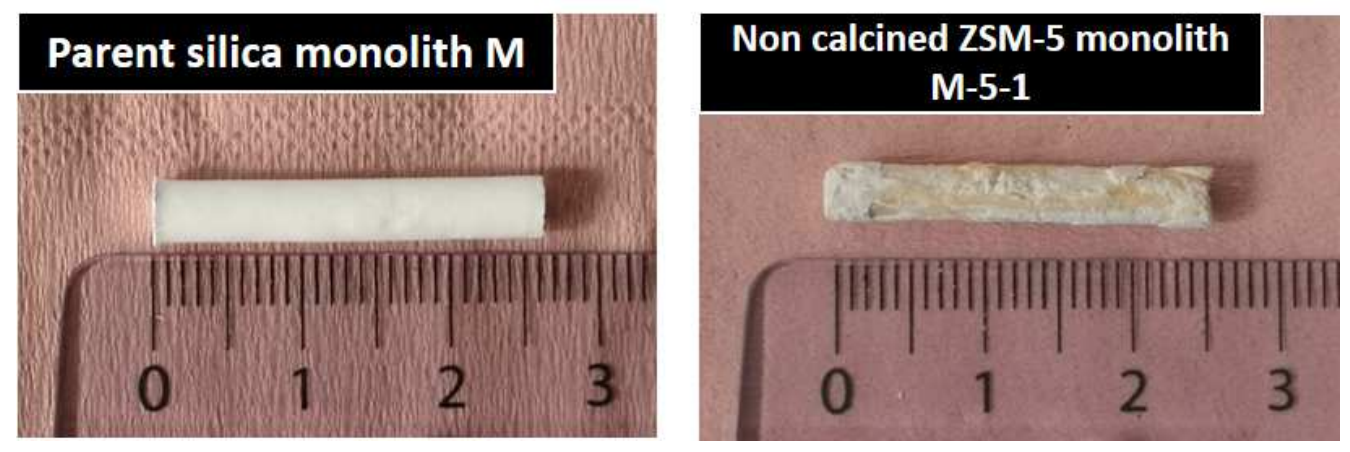

Figure 6. Photographs showing the shape conservation of the obtained monolith after pseudomorphic transformation

SEM images show the change in morphology of all samples after hydrothermal treatment: the amorphous silica skeleton has crystallized into ZSM-5 zeolite with nanosheet morphology in all cases (Fig. 7). The monolith skeleton is constituted by spheres with a size of $4-6 \mu \mathrm{m}$ composed by 
a lamellar stacking of ZSM-5 nanosheets assembled together in the shape of a house of cards. The size of the ZSM-5 nanosheets spheres increases slightly with the duration of the hydrothermal treatment at $120{ }^{\circ} \mathrm{C}$ to reach 6-8 $\mu \mathrm{m}$ after 5 days. Moreover, a decrease of the space between the stacked sheets that almost disappears after 5 days at $120^{\circ} \mathrm{C}$ was also observed. The TEM images confirm the nanosheet morphology with an average thickness of $2 \mathrm{~nm}$ for M-5-1 (Fig. 8a). 

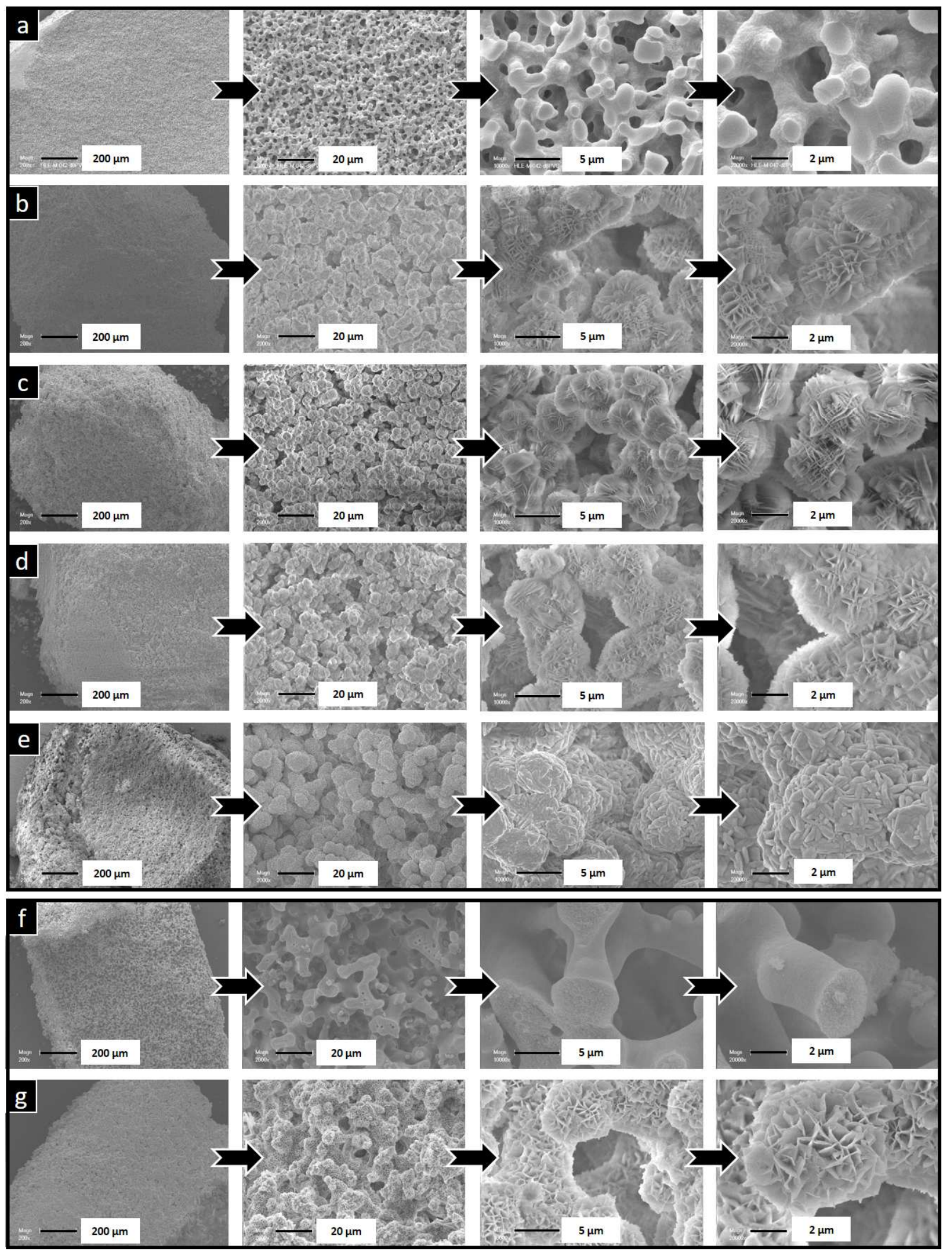
Figure 7. SEM images of (a) the parent silica monolith $\mathrm{M}$, and (f) monolith $\mathrm{N}$ and the obtained ZSM-5 nanosheets monoliths (b) M-5-0, (c) M-5-1, (d) M-5-2, (e) M-5-5, and (g) N-5-1
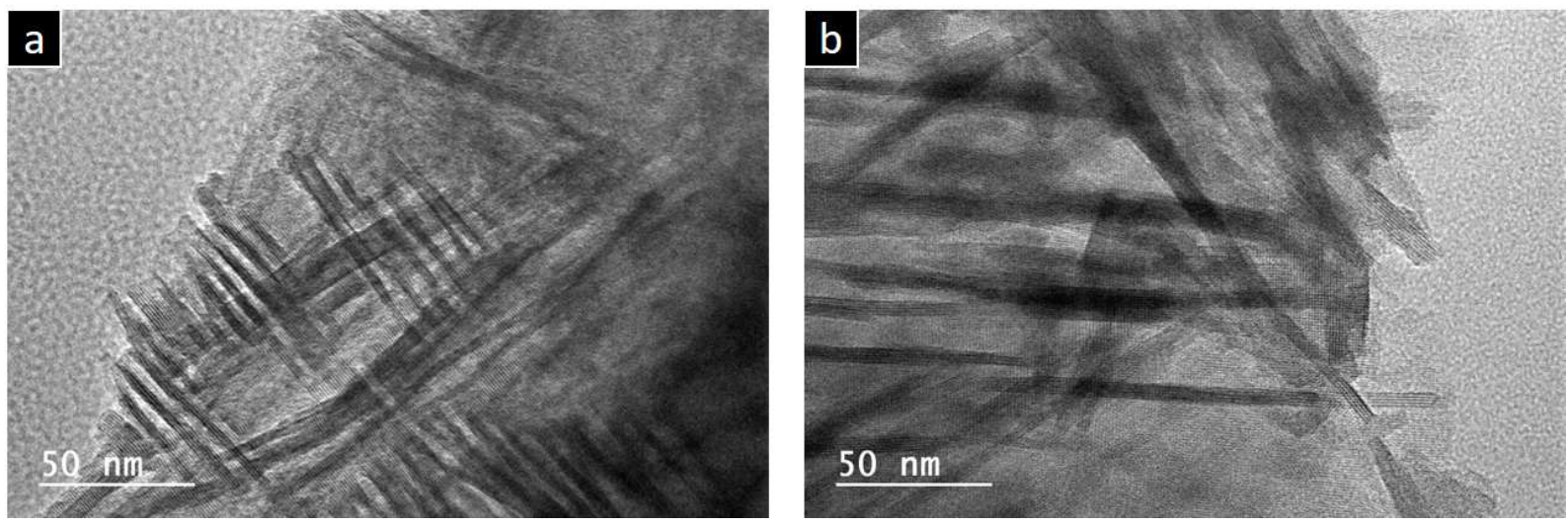

Figure 8. TEM images of monoliths (a) M-5-1 and (b) N-5-1

The $\mathrm{N}_{2}$ sorption isotherms of the calcined monoliths obtained after different durations of the hydrothermal treatment at $120{ }^{\circ} \mathrm{C}$ are a mixture type I at low $\mathrm{p} / \mathrm{p}^{\circ}$ and type II-b at high $\mathrm{p} / \mathrm{p}^{\circ}$ (Fig. 9a) ${ }^{64}$. The hysteresis in the relative pressure range $0.4<\mathrm{p} / \mathrm{p}^{\circ}<1$ is characteristic of slit pores resulting from the stacking of the nanosheets. The inflexions observed on the isotherms of M-5-0, M-5-1 and M-5-2 monoliths at $\mathrm{p} / \mathrm{p}^{\circ}$ of about $0.3-0.4$ indicate a capillary condensation in small mesopores created during the formation of ZSM-5 nanosheets. Indeed, there is no capillary condensation observed on the isotherm of the parent monolith. The textural properties determined from the $\mathrm{N}_{2}$ sorption experiments are reported in Table 2. 


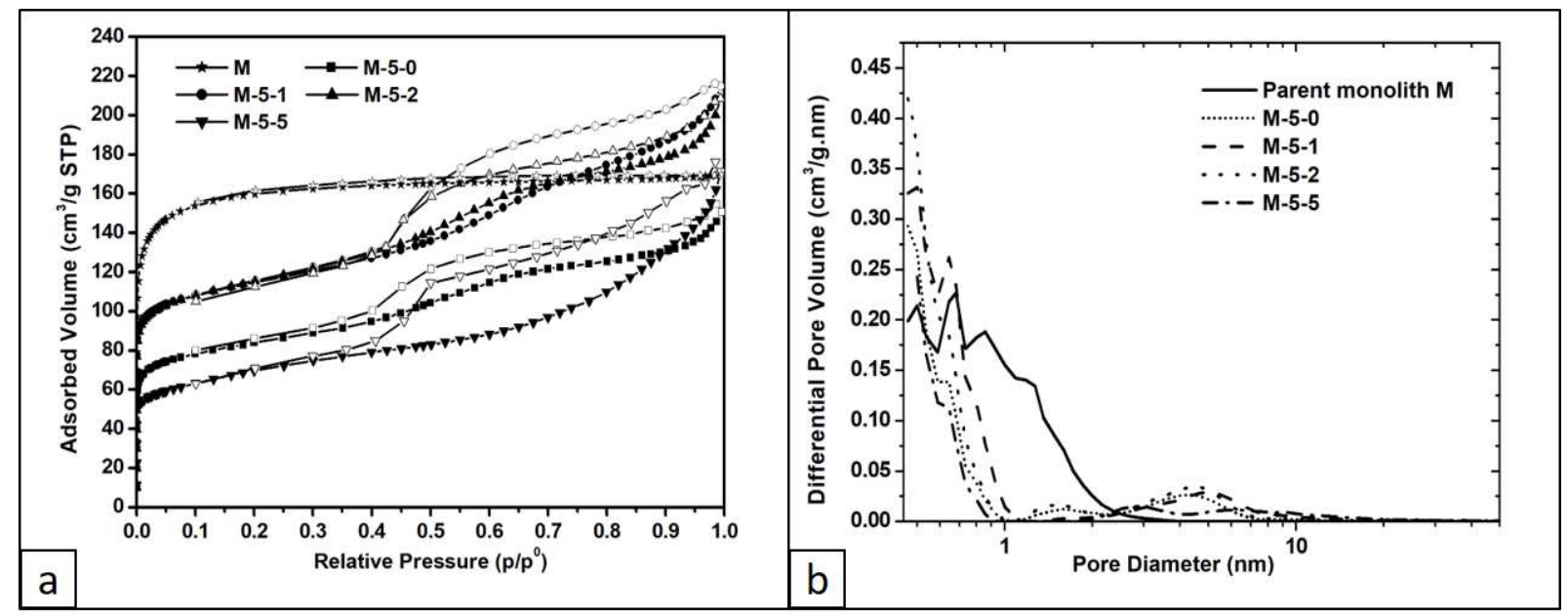

Figure 9. (a) $\mathrm{N}_{2}$ adsorption/desorption isotherms at $77 \mathrm{~K}$ and (b) pore size distributions of the parent $\mathrm{M}$ monolith and all obtained monoliths after calcination

Micropores with sizes $<1 \mathrm{~nm}$ that are assigned to the zeolite framework and secondary micropores of $1.5 \mathrm{~nm}$ size are observed on the pore size distributions of synthesized monoliths (Fig. 9b). The microporous volume of the secondary micropores remains constant $\left(0.01 \mathrm{~cm}^{3} / \mathrm{g}\right)$ whatever the duration of the hydrothermal treatment at $120^{\circ} \mathrm{C}$. It is assumed that these secondary micropores are formed during the crystallization of ZSM-5 nanosheets because of the presence of the bifunctional organic agent. Indeed, secondary micropores of $1.59 \mathrm{~nm}$ diameter were also observed for ZSM-5 nanosheets powder and conventional MFI microcrystals have only zeolitic micropores with size $<1 \mathrm{~nm}$ with a microporous volume of $0.12 \mathrm{~cm}^{3} / \mathrm{g}{ }^{57}$. An increase of the zeolitic microporous volume from $0.07 \mathrm{~cm}^{3} / \mathrm{g}(\mathrm{M}-5-0)$ to $0.12 \mathrm{~cm}^{3} / \mathrm{g}(\mathrm{M}-5-1)$ is observed with an additional 1-day hydrothermal treatment at $120{ }^{\circ} \mathrm{C}$ in static mode (Table 2). But, the microporous volume decreases slightly to $0.11 \mathrm{~cm}^{3} / \mathrm{g}$ after 2 days at $120{ }^{\circ} \mathrm{C}$ (M-5-2) and in a more pronounced way to reach $0.06 \mathrm{~cm}^{3} / \mathrm{g}$ after 5 days at $120^{\circ} \mathrm{C}(\mathrm{M}-5-5)$, because of the redissolution of the nanosheets that 
generates bigger particles not completely crystallized. The crystallization rates of obtained ZSM-5 nanosheets monoliths were calculated by comparing the zeolitic micropores volume to the microporous volumes of ZSM-5 nanosheets powder $\left(0.12 \mathrm{~cm}^{3} / \mathrm{g}\right)$ and revealed a total crystallization for M-5-1 (Table 2).

Table 2. Textural characteristics and crystallization rates of the calcined ZSM-5 nanosheets monoliths

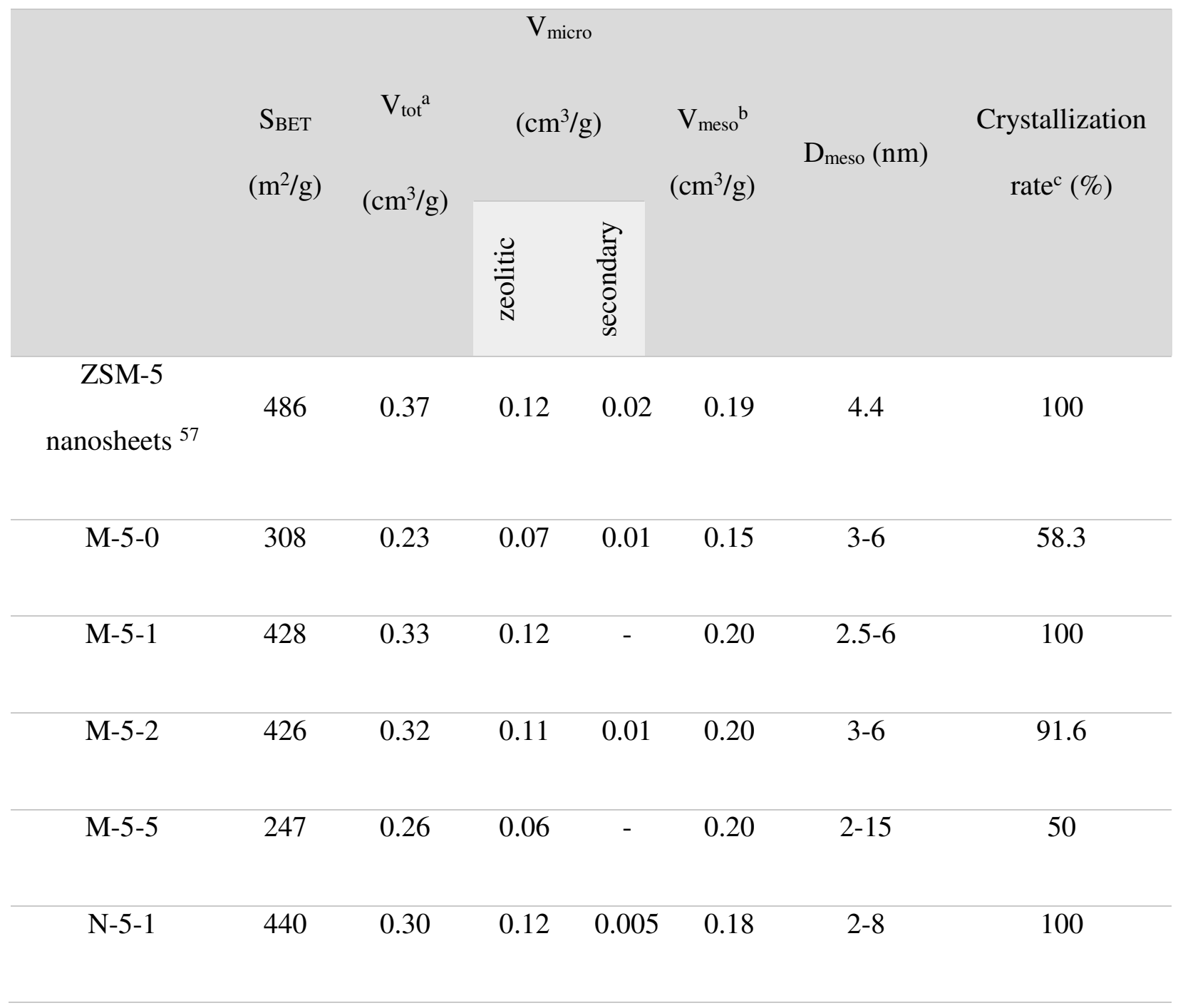


${ }^{a}$ It is noteworthy that for all samples the presence of large mesopores does not allow determining accurately the total pore volume

${ }^{b}$ Mesoporous volume: $V_{\text {meso }}=V_{\text {tot }}-V_{\text {mircro total }}$

${ }^{c}$ Crystallisation rate $=V_{\text {micro zeolitic }} / V_{\text {micro zeolitic of reference ZSM-5 nanosheets }} ; V_{\text {micro zeolitic of reference ZSM-5 nanosheets }}=0.12 \mathrm{~cm}^{3} / \mathrm{g}$

Mercury intrusion experiment was run for the sample M-5-1 with the highest crystallization rate (Fig. 10). One step is observed corresponding to a macroporous volume of $0.30 \mathrm{~mL} / \mathrm{g}$. It is noteworthy that the macropores size around $4.5 \mu \mathrm{m}$ was conserved after pseudomorphic transformation with a highly polydisperse distribution compared to the parent amorphous silica monolith that have a narrow distribution of macropores size. Indeed, pore size distribution reveals also the presence of meso-/macropores with broad distribution ranging from 20 to $200 \mathrm{~nm}$ and mesopores of $8 \mathrm{~nm}$ with narrow distribution. These additional meso/macropores are the result of the stacking of the nanosheets and of the spherical aggregates of nanosheets.

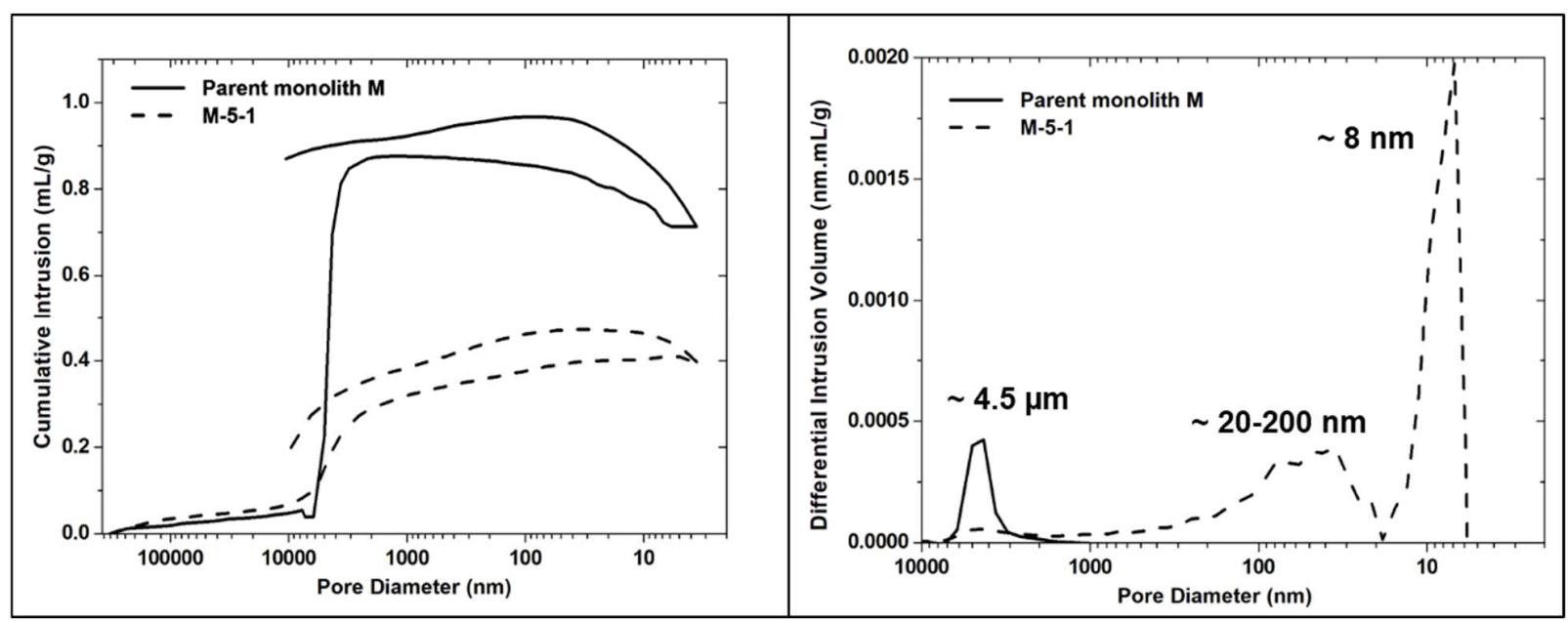


Figure 10. Mercury intrusion/extrusion curves (left) and pore size distributions (right) of the parent silica monolith $\mathrm{M}$ and the obtained monolith $\mathrm{M}-5-1$ after calcination

ZSM-5 nanosheets monolith synthesized from meso/macroporous silica monolith. The optimal conditions (i.e. 5 days at $150{ }^{\circ} \mathrm{C}$ under stirring and 1 day at $120{ }^{\circ} \mathrm{C}$ in static mode) observed for the synthesis of ZSM-5 nanosheets monoliths from micro/macroporous silica monolith M have been applied to transform the meso/macroporous silica monolith $\mathrm{N}$ into a monolith composed by ZSM5 nanosheets.

The photographs of the parent monolith $\mathrm{N}$ and the obtained monolith after pseudomorphic transformation are displayed in Fig. S3 and show that the shape was conserved but the diameter of the monolith was reduced to $70 \%$ compared to the diameter of the parent silica monolith $\mathrm{N}(0.50$ $\mathrm{cm}$ for monolith $\mathrm{N}$ vs $0.35 \mathrm{~cm}$ for monolith $\mathrm{N}-5-1$ ). Erosion also observed for monolith $\mathrm{M}$ appears more important for monolith $\mathrm{N}$. It is assumed that it is the result of the additional mesoporosity that has increased the dissolution rates while re-precipitation rates were maintained.

XRD patterns of the obtained monolith $\mathrm{N}-5-1$ show peaks corresponding to the reflections (h01) characteristic of a pure MFI-type zeolite phase, which is consistent with the inhibition of growth along the b-axis characteristic of ZSM-5 nanosheets (Fig. 5).

SEM images show that the amorphous silica skeleton is crystallized into ZSM-5 zeolite with nanosheets morphology (Fig. 7). Compared to the M-5-1 the morphology of N-5-1 is slightly different with ZSM-5 nanosheets forming a more continuous network and not spherical aggregates. The TEM image displayed in Fig. $8 \mathrm{~b}$ confirms the nanosheet morphology with an average thickness of $2 \mathrm{~nm}$. 
The $\mathrm{N}_{2}$ adsorption/desorption isotherm of monolith $\mathrm{N}-5-1$ displayed in Fig. 11 is very similar to the one of M-5-1 monolith and the textural properties are similar (Table 2). The zeolitic microporous volume of $0.12 \mathrm{~cm}^{3} / \mathrm{g}$ corresponds to a crystallization rate of $100 \%$ and the mesopores size is ranging from 2 to $8 \mathrm{~nm}$.

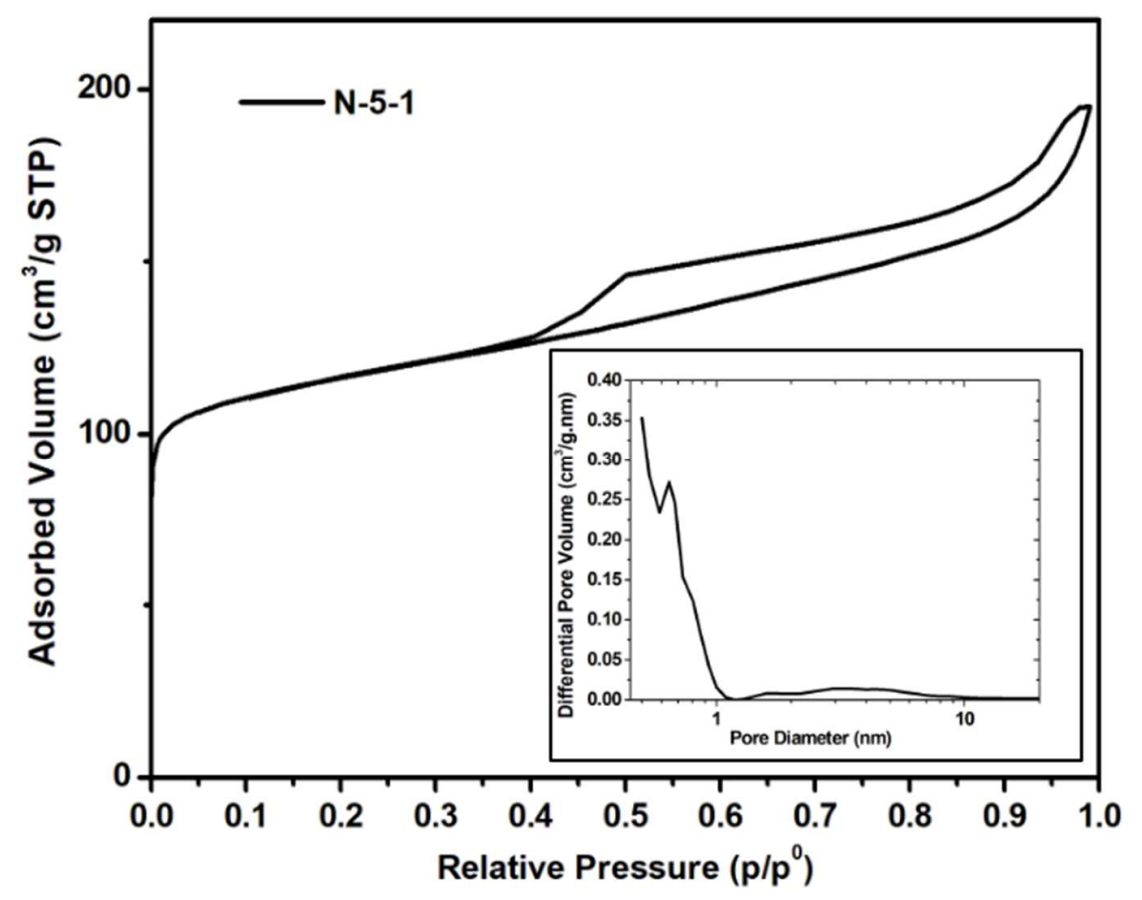

Figure 11. $\mathrm{N}_{2}$ adsorption-desorption isotherms and pore size distributions (inset) of the obtained N-5-1 monolith

Monoliths N and N-5-1 were characterized by mercury intrusion-extrusion. Fig. 12 displays their mercury intrusion-extrusion curves and pore size distributions. For monolith N-5-1, 2 distinct steps are observed: one for macropores of average size of $8 \mu \mathrm{m}$ corresponding to a macroporous volume 
of $0.97 \mathrm{~mL} / \mathrm{g}$, smaller than the macroporous volume of the parent amorphous monolith $(1.40 \mathrm{~mL} / \mathrm{g})$ and one for smaller macropores pores ranging between 30 and $400 \mathrm{~nm}$ and centered at $80 \mathrm{~nm}$, which contribute to an additional pore volume of $0.15 \mathrm{~mL} / \mathrm{g}$. It is noteworthy the conservation of the macropores with an average diameter around $8 \mu \mathrm{m}$ after pseudomorphic transformation but with a wider distribution between 3.5 and $14 \mu \mathrm{m}$ compared to the narrow macropores size distribution (between 6 and $10 \mu \mathrm{m}$ ) observed for the parent silica monolith. Mesopores observed by mercury intrusion in the parent silica monolith are no more observed after pseudomorphic transformation. However, mesopores were observed by $\mathrm{N}_{2}$ adsorption/desorption experiments as well as in the M-5-1 monoliths and attributed to the mesopores created after the elimination of the organic agent between the nanosheets packages by calcination (nanosheets do not collapse perfectly after calcination).

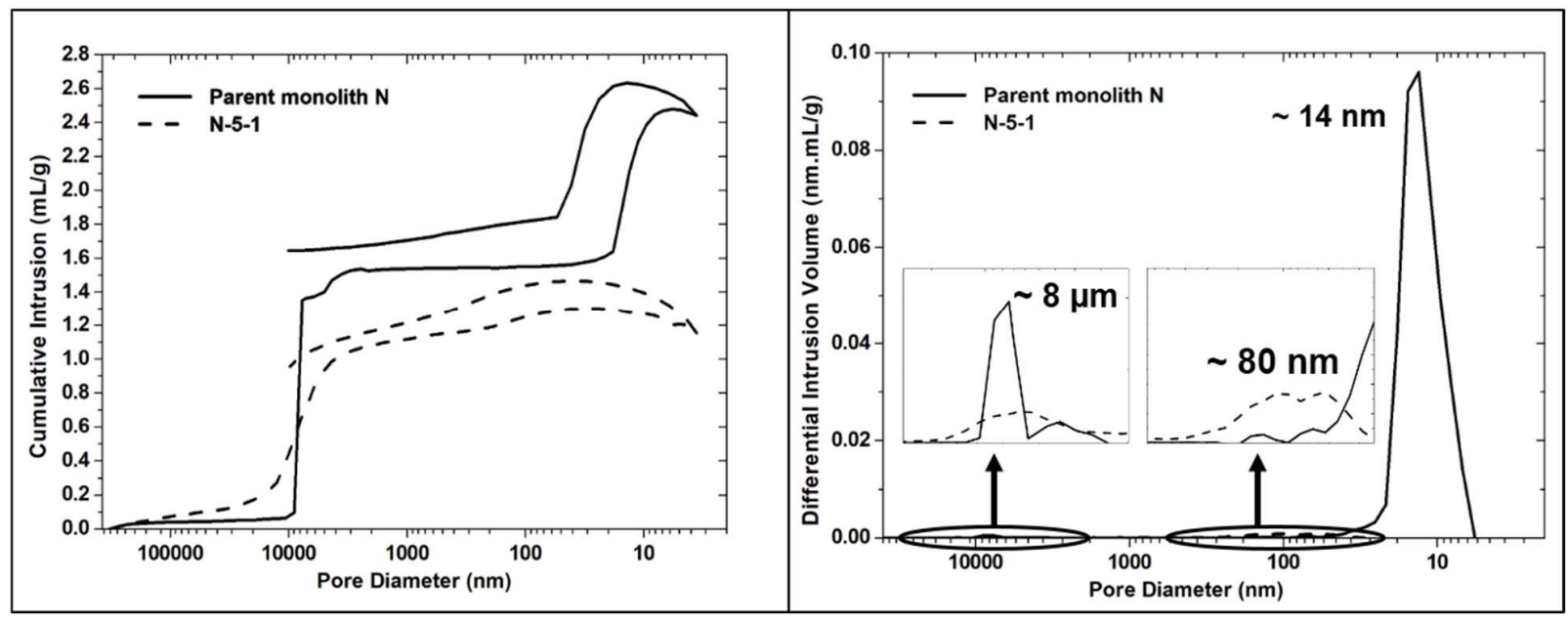

Figure 12. Mercury intrusion-extrusion curves (left) and pore size distributions (right) of the parent silica monolith $\mathrm{N}$ and the obtained monolith after transformation $\mathrm{N}-5-1$ 
The ZSM-5 nanosheet monolith "M-5-1" and "N-5-1" were analyzed by TGA and two main weight losses were observed from 20 and $800{ }^{\circ} \mathrm{C}$ (Table S1). The one (3-4 wt.\%) in the temperature range $30-110{ }^{\circ} \mathrm{C}$ corresponds to physisorbed water and the second one $(27-28 \%$ wt. $\%)$ in the temperature range $110-700{ }^{\circ} \mathrm{C}$ corresponds to the decomposition of the bifunctional structuring agent. There are 2 organic cations per unit cell in ZSM-5 zeolite and thus a weight loss of $16.5 \mathrm{wt} . \%$ is expected 43,66. However, the weight loss attributing to the decomposition of the organic cations is higher indicating an excess of $\mathrm{C}_{22-6-6}$ surfactant as usually observed for zeolite nanosheets ${ }^{68,69}$ and/or some dehydroxylation due the presence of defects.

The molar Si/Al ratio from ICP-OES data for "M-5-1" and "N-5-1" are reported in Table S1. The two monoliths show a high Si/Al ratio of 350 and 182 for M-5-1 and N-5-1, respectively. This $\mathrm{Si} / \mathrm{Al}$ is much higher than those measured for ZSM-5 nanosheets beads synthesized under the same conditions (about 40) ${ }^{57}$.

It is noteworthy that the ZSM-5 nanosheets monoliths remained intact after the mercury intrusionextrusion experiments under a pressure of $400 \mathrm{MPa}$ reflecting a significant mechanical stability (Fig. 13).
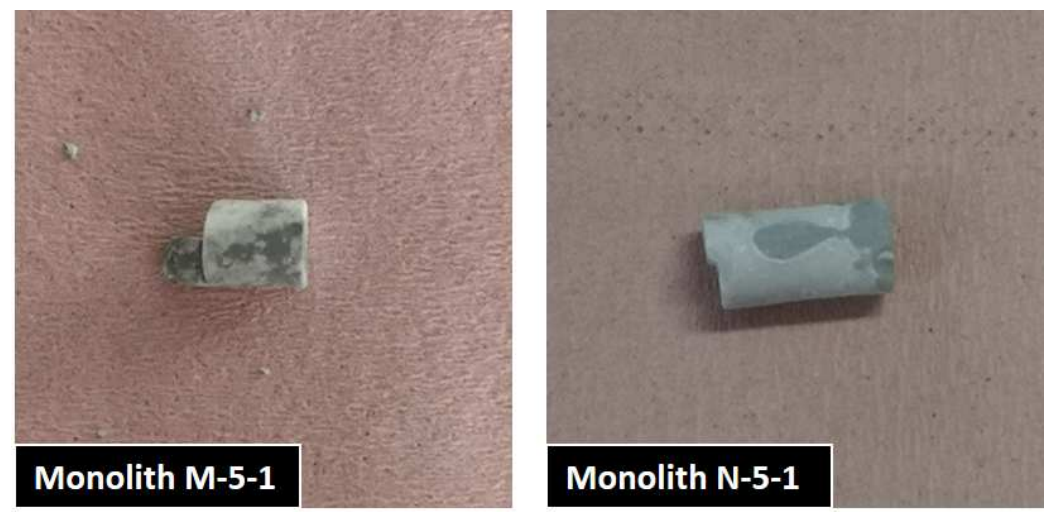
Figure 13. Photographs of the synthetized monoliths M-5-1 and N-5-1 after mercury intrusionextrusion experiments

\section{CONCLUSION}

Mechanically stable cylindrical macroporous silica monoliths with only microporosity inside the silica skeleton were obtained by optimizing the hydrodynamic regime during ripening phase of the synthesis. The good stirring rate with a suitable duration contributed efficiently to the concurrence of phase separation and silica condensation processes and further to the compact agglomeration of silica particles creating a densified silica wall. In addition, macroporous silica monoliths with disordered mesoporosity were generated by applying a treatment step in basic medium to wet silica monoliths with only microporosity.

These two types of silica monoliths having different types of pores, micro/macropores and meso/macropores, have been successfully transformed by following a pseudomorphism process into ZSM-5 monoliths with nanosheets morphology featuring hierarchical porosities. The formation of ZSM-5 nanosheets from the amorphous silica skeleton of the monoliths was evidenced by XRD that showed the only presence of h01 reflections characteristic of MFI zeolite with inhibition growth along the $b$-axis. The first attempt was carried out on the micro/macroporous silica type monolith. A first 5-day treatment at $150{ }^{\circ} \mathrm{C}$ with stirring was found suitable to maintain the macroscopic shape of the monolith but not sufficient to obtain a fully crystallized ZSM-5 monolith. Further crystallization was achieved without losing the monolith shape after an additional treatment at $120^{\circ} \mathrm{C}$ under static conditions. A fully crystallized ZSM-5 monolith with nanosheet morphology has been obtained after 1 day of supplementary hydrothermal treatment at 
$120^{\circ} \mathrm{C}$. This latter features 3 levels of hierarchical porosity: macropores with an average diameter centered at $4.5 \mu \mathrm{m}$ similar to the parent silica monolith and a volume of $0.30 \mathrm{~mL} / \mathrm{g}$, secondary meso-/macropores with broad distribution size ranging from 20 to $200 \mathrm{~nm}$ and mesopores of $8 \mathrm{~nm}$ with narrow size distribution resulting of the stacking of the nanosheets and of the spherical aggregates of nanosheets. The optimal conditions found for the previously discussed monolith (5 days at $150{ }^{\circ} \mathrm{C}$ under stirring and 1 day at $120{ }^{\circ} \mathrm{C}$ in static mode) have been applied to transform a meso/macroporous silica monolith. The obtained monolith was fully crystallized into ZSM-5 monolith nanosheets and present macropores with a main diameter centered at $8 \mu \mathrm{m}$ similar to the macropores size of the parent silica monolith with a volume of $0.97 \mathrm{~mL} / \mathrm{g}$, and secondary macropores centered at $80 \mathrm{~nm}$ contributing to an additional pore volume of $0.15 \mathrm{~mL} / \mathrm{g}$.

Both ZSM-5 nanosheets monoliths obtained from micro/macroporous and meso/macroporous silica monoliths by following the same experimental protocol have similar textural characteristics although mercury intrusion experiments showed some differences. Such hierarchically porous ZSM-5 monoliths with nanosheets morphology are expected to be very efficient for use in continuous flow process and industrial applications.

\section{ASSOCIATED CONTENT}

\section{Supporting Information.}

Figure $\mathrm{S} 1 . \mathrm{N}_{2}$ adsorption-desorption isotherms and pore size distribution (inset) of the parent silica monolith $\mathrm{N}$

Figure S2. Photographs of the calcined monoliths after pseudomorphic transformation 
Figure S3. Photographs of parent silica monolith N and ZSM-5 nanosheets monolith N-5-1

Table S1. Experimental weight losses measured by thermogravimetric analysis and Si/Al ratio measured by ICP-OES of the obtained monoliths

\section{AUTHOR INFORMATION}

\section{Corresponding Authors}

*E-mail: benedicte.lebeau@uha.fr ; jean.daou@uha.fr. Phone: +33389336882; +33389336739. Fax: +33389896885

\section{ORCID}

Bénédicte Lebeau : 0000-0001-7447-6042 ; T. Jean Daou : 0000-0002-9973-3372

\section{Author Contributions}

T. Jean Daou and Bénédicte Lebeau: Conceptualization, Magali Bonne, Joumana Toufaily, Tayssir Hamieh, T. Jean Daou and Bénédicte Lebeau: Supervision, Kassem Moukahhal, Huu Nghia Le, T. Jean Daou and Bénédicte Lebeau: Writing - Original Draft, Kassem Moukahhal, Huu Nghia Le, Magali Bonne, T. Jean Daou and Bénédicte Lebeau: Review \& Editing. Kassem Moukahhal and Huu Nghia Le: Performing the experiments.

All authors have given approval to the final version of the manuscript.

\section{ACKNOWLEDGMENT}


The XRD, adsorption, AMTR and ME platforms of IS2M are acknowledged. Laure Michelin, Habiba Nouali, Ludovic Josien and Loïc Vidal are warmly thanked for their help in XRD, $\mathrm{N}_{2}$ adsorption/desorption, SEM and TEM data, respectively.

\section{REFERENCES}

(1) Kabalan, I.; Khay, I.; Nouali, H.; Ryzhikov, A.; Lebeau, B.; Albrecht, S.; Rigolet, S.; Fadlallah, M.-B.; Toufaily, J.; Hamieh, T.; Patarin, J.; Daou, T. J. Influence of the Particle Sizes on the Energetic Performances of MFI-Type Zeolites. J. Phys. Chem. C 2015, 119, 18074-18083. https://doi.org/10.1021/acs.jpcc.5b04484.

(2) Huve, J.; Ryzhikov, A.; Nouali, H.; Lalia, V.; Augé, G.; Daou, T. J. Porous Sorbents for the Capture of Radioactive Iodine Compounds: A Review. RSC Adv. 2018, 8, 29248-29273. https://doi.org/10.1039/C8RA04775H.

(3) Said, A.; Nouali, H.; Limousy, L.; Dutournié, P.; Josien, L.; Toufaily, J.; Hamieh, T.; Daou, T. J. Synthesis of Mono- and Bi-Layer Zeolite Films on Alumina Substrates. C. R. Chim 2016, 19, 486-495. https://doi.org/10.1016/j.crci.2015.09.018.

(4) Rioland, G.; Nouali, H.; Daou, T. J.; Faye, D.; Patarin, J. Adsorption of Volatile Organic Compounds in Composite Zeolites Pellets for Space Decontamination. Adsorption 2017, 23, 395-403. https://doi.org/10.1007/s10450-017-9870-9.

(5) Li, Y.; Yu, J. New Stories of Zeolite Structures: Their Descriptions, Determinations, Predictions, and Evaluations. Chem. Rev. 2014, 114, 7268-7316. https://doi.org/10.1021/cr500010r. 
(6) Martínez, C.; Corma, A. Inorganic Molecular Sieves: Preparation, Modification and Industrial Application in Catalytic Processes. Coordin. Chem. Rev. 2011, 255, 1558-1580. https://doi.org/10.1016/j.ccr.2011.03.014.

(7) Li, C.; Moliner, M.; Corma, A. Building Zeolites from Precrystallized Units: Nanoscale Architecture. Angew. Chem. Int. Ed. 2018, 57, 15330-15353. https://doi.org/10.1002/anie.201711422.

(8) Sachse, A.; García-Martínez, J. Surfactant-Templating of Zeolites: From Design to Application. $\quad$ Chem. $\quad$ Mater. $2017, \quad 3827-3853$. https://doi.org/10.1021/acs.chemmater.7b00599.

(9) Dusselier, M.; Davis, M. E. Small-Pore Zeolites: Synthesis and Catalysis. Chem. Rev. 2018, 118, 5265-5329. https://doi.org/10.1021/acs.chemrev.7b00738.

(10) Li, J.; Corma, A.; Yu, J. Synthesis of New Zeolite Structures. Chem. Soc. Rev. 2015, 44, 7112-7127. https://doi.org/10.1039/C5CS00023H.

(11) Přech, J.; Pizarro, P.; Serrano, D. P.; Čejka, J. From 3D to 2D Zeolite Catalytic Materials. Chem. Soc. Rev. 2018, 47, 8263-8306. https://doi.org/10.1039/C8CS00370J.

(12) Schneider, D.; Mehlhorn, D.; Zeigermann, P.; Kärger, J.; Valiullin, R. Transport Properties of Hierarchical Micro-Mesoporous Materials. Chem. Soc. Rev. 2016, 45, 3439-3467. https://doi.org/10.1039/C5CS00715A.

(13) Bingre, R.; Louis, B.; Nguyen, P. An Overview on Zeolite Shaping Technology and Solutions to Overcome Diffusion Limitations. Catalysts 2018, 8, 163. https://doi.org/10.3390/catal8040163.

(14) Awala, H.; Gilson, J.-P.; Retoux, R.; Boullay, P.; Goupil, J.-M.; Valtchev, V.; Mintova, S. Template-Free Nanosized Faujasite-Type Zeolites. Nature Mater 2015, 14, 447-451. https://doi.org/10.1038/nmat4173. 
(15) Mintova, S.; Jaber, M.; Valtchev, V. Nanosized Microporous Crystals: Emerging Applications. Chem. Soc. Rev. 2015, 44, 7207-7233. https://doi.org/10.1039/C5CS00210A.

(16) Zaarour, M.; Dong, B.; Naydenova, I.; Retoux, R.; Mintova, S. Progress in Zeolite Synthesis Promotes Advanced Applications. Micropor. Mesopor. Mat. 2014, 189, 11-21. https://doi.org/10.1016/j.micromeso.2013.08.014.

(17) Bai, R.; Sun, Q.; Wang, N.; Zou, Y.; Guo, G.; Iborra, S.; Corma, A.; Yu, J. Simple Quaternary Ammonium Cations-Templated Syntheses of Extra-Large Pore Germanosilicate Zeolites. Chem. Mater. 2016, 28, 6455-6458. https://doi.org/10.1021/acs.chemmater.6b03179.

(18) Jiang, J.; Yun, Y.; Zou, X.; Jorda, J. L.; Corma, A. ITQ-54: A Multi-Dimensional ExtraLarge Pore Zeolite with $20 \times 14 \times 12$-Ring Channels. Chem. Sci. 2015, 6, 480-485. https://doi.org/10.1039/C4SC02577F.

(19) Yang, J.; Zhang, Y.-B.; Liu, Q.; Trickett, C. A.; Gutiérrez-Puebla, E.; Monge, M. Á.; Cong, H.; Aldossary, A.; Deng, H.; Yaghi, O. M. Principles of Designing Extra-Large Pore Openings and Cages in Zeolitic Imidazolate Frameworks. J. Am. Chem. Soc. 2017, 139, 6448-6455. https://doi.org/10.1021/jacs.7b02272.

(20) Smeets, S.; Xie, D.; Baerlocher, C.; McCusker, L. B.; Wan, W.; Zou, X.; Zones, S. I. HighSilica Zeolite SSZ-61 with Dumbbell-Shaped Extra-Large-Pore Channels. Angew. Chem. Int. Ed. 2014, 53, 10398-10402. https://doi.org/10.1002/anie.201405658.

(21) Kang, J. H.; Xie, D.; Zones, S. I.; Smeets, S.; McCusker, L. B.; Davis, M. E. Synthesis and Characterization of CIT-13, a Germanosilicate Molecular Sieve with Extra-Large Pore Openings. Chem. Mater. 2016, 6250-6259. https://doi.org/10.1021/acs.chemmater.6b02468. 
(22) Schwieger, W.; Machoke, A. G.; Weissenberger, T.; Inayat, A.; Selvam, T.; Klumpp, M.; Inayat, A. Hierarchy Concepts: Classification and Preparation Strategies for Zeolite Containing Materials with Hierarchical Porosity. Chem. Soc. Rev. 2016, 45, 3353-3376. https://doi.org/10.1039/C5CS00599J.

(23) Chen, L.-H.; Li, X.-Y.; Rooke, J. C.; Zhang, Y.-H.; Yang, X.-Y.; Tang, Y.; Xiao, F.-S.; Su, B.-L. Hierarchically Structured Zeolites: Synthesis, Mass Transport Properties and Applications. J. Mater. Chem. 2012, 22, 17381. https://doi.org/10.1039/c2jm31957h.

(24) Sun, M.-H.; Huang, S.-Z.; Chen, L.-H.; Li, Y.; Yang, X.-Y.; Yuan, Z.-Y.; Su, B.-L. Applications of Hierarchically Structured Porous Materials from Energy Storage and Conversion, Catalysis, Photocatalysis, Adsorption, Separation, and Sensing to Biomedicine. Chem. Soc. Rev. 2016, 45, 3479-3563. https://doi.org/10.1039/C6CS00135A.

(25) Pérez-Ramírez, J.; Christensen, C. H.; Egeblad, K.; Christensen, C. H.; Groen, J. C. Hierarchical Zeolites: Enhanced Utilisation of Microporous Crystals in Catalysis by Advances in Materials Design. Chem. Soc. Rev. 2008, 37, 2530. https://doi.org/10.1039/b809030k.

(26) El Hanache, L.; Lebeau, B.; Nouali, H.; Toufaily, J.; Hamieh, T.; Daou, T. J. Performance of Surfactant-Modified *BEA-Type Zeolite Nanosponges for the Removal of Nitrate in Contaminated Water: Effect of the External Surface. J. Hazard. Mater. 2019, 364, 206-217. https://doi.org/10.1016/j.jhazmat.2018.10.015.

(27) Astafan, A.; Benghalem, M. A.; Pouilloux, Y.; Patarin, J.; Bats, N.; Bouchy, C.; Daou, T. J.; Pinard, L. Particular Properties of the Coke Formed on Nano-Sponge *BEA Zeolite during Ethanol-to-Hydrocarbons Transformation. J. Catal. 2016, 336, 1-10. https://doi.org/10.1016/j.jcat.2016.01.002. 
(28) Kabalan, I.; Lebeau, B.; Fadlallah, M.-B.; Toufaily, J.; Hamieh, T.; Bellat, J. P.; Daou, T. J. Hierarchical Faujasite-Type Zeolite for Molecular Decontamination. J. Nanosci. Nanotechnol. 2016, 16, 9318-9322. https://doi.org/10.1166/jnn.2016.12884.

(29) Hua, Z. L.; Zhou, J.; Shi, J. L. Recent Advances in Hierarchically Structured Zeolites: Synthesis and Material Performances. Chem. Commun. 2011, 47, 10536. https://doi.org/10.1039/c1cc10261c.

(30) Na, K.; Choi, M.; Ryoo, R. Recent Advances in the Synthesis of Hierarchically Nanoporous Zeolites. Micropor. Mesopor. Mat. 2013, 166, 3-19. https://doi.org/10.1016/j.micromeso.2012.03.054.

(31) Groen, J. C.; Bach, T.; Ziese, U.; Paulaime-van Donk, A. M.; de Jong, K. P.; Moulijn, J. A.; Pérez-Ramírez, J. Creation of Hollow Zeolite Architectures by Controlled Desilication of Al-Zoned ZSM-5 Crystals. J. Am. Chem. Soc. 2005, 127, 10792-10793. https://doi.org/10.1021/ja052592x.

(32) Ryoo, R.; Joo, S. H.; Kruk, M.; Jaroniec, M. Ordered Mesoporous Carbons. Adv. Mater. 2001, 13, 677-681. https://doi.org/10.1002/1521-4095(200105)13:9<677::AIDADMA677>3.0.CO;2-C.

(33) Fang, Y.; Hu, H. An Ordered Mesoporous Aluminosilicate with Completely Crystalline Zeolite Wall Structure. J. Am. Chem. Soc. 2006, 128, 10636-10637. https://doi.org/10.1021/ja0611821.

(34) Fan, W.; Snyder, M. A.; Kumar, S.; Lee, P.-S.; Yoo, W. C.; McCormick, A. V.; Lee Penn, R.; Stein, A.; Tsapatsis, M. Hierarchical Nanofabrication of Microporous Crystals with Ordered Mesoporosity. Nat. Mater. 2008, 7, 984-991. https://doi.org/10.1038/nmat2302.

(35) Ciesla, U.; Schüth, F. Ordered Mesoporous Materials. Micropor. Mesopor. Mat. 1999, 27, 131-149. https://doi.org/10.1016/S1387-1811(98)00249-2. 
(36) Monnier, A.; Schüth, F.; Huo, Q.; Kumar, D.; Margolese, D.; Maxwell, R. S.; Stucky, G. D.; Krishnamurty, M.; Petroff, P.; Firouzi, A.; Janicke, M.; Chmelka, B. F. Cooperative Formation of Inorganic-Organic Interfaces in the Synthesis of Silicate Mesostructures. Science 1993, 261, 1299-1303. https://doi.org/10.1126/science.261.5126.1299.

(37) Hartmann, M. Ordered Mesoporous Materials for Bioadsorption and Biocatalysis. Chem. Mater. 2005, 17, 4577-4593. https://doi.org/10.1021/cm0485658.

(38) Xia, Y.; Mokaya, R. On the Synthesis and Characterization of ZSM-5/MCM-48 Aluminosilicate Composite Materials. J. Mater. Chem. 2004, 14, 863-870. https://doi.org/10.1039/B313389C.

(39) Prokešová, P.; Mintova, S.; Čejka, J.; Bein, T. Preparation of Nanosized Micro/Mesoporous Composites via Simultaneous Synthesis of Beta/MCM-48 Phases. Micropor. Mesopor. Mat. 2003, 64, 165-174. https://doi.org/10.1016/S1387-1811(03)00464-5.

(40) Galarneau, A.; Cambon, H.; Renzo, F. D.; Ryoo, R.; Choi, M.; Fajula, F. Microporosity and Connections between Pores in SBA-15 Mesostructured Silicas as a Function of the Temperature of Synthesis. New J. Chem. 2003, 27, 73-79. https://doi.org/10.1039/B207378C.

(41) Choi, M.; Na, K.; Kim, J.; Sakamoto, Y.; Terasaki, O.; Ryoo, R. Stable Single-Unit-Cell Nanosheets of Zeolite MFI as Active and Long-Lived Catalysts. Nature 2009, 461, 246249. https://doi.org/10.1038/nature08288.

(42) Na, K.; Jo, C.; Kim, J.; Cho, K.; Jung, J.; Seo, Y.; Messinger, R. J.; Chmelka, B. F.; Ryoo, R. Directing Zeolite Structures into Hierarchically Nanoporous Architectures. Science 2011, 333, 328-332. https://doi.org/10.1126/science.1204452.

(43) Dhainaut, J.; Daou, T. J.; Bidal, Y.; Bats, N.; Harbuzaru, B.; Lapisardi, G.; Chaumeil, H.; Defoin, A.; Rouleau, L.; Patarin, J. One-Pot Structural Conversion of Magadiite into MFI 
Zeolite Nanosheets Using Mononitrogen Surfactants as Structure and Shape-Directing Agents. CrystEngComm 2013, 15, 3009. https://doi.org/10.1039/c3ce40118a.

(44) Kabalan, I.; Rioland, G.; Nouali, H.; Lebeau, B.; Rigolet, S.; Fadlallah, M.-B.; Toufaily, J.; Hamiyeh, T.; Daou, T. J. Synthesis of Purely Silica MFI-Type Nanosheets for Molecular Decontamination. $R S C A d v$. 2014, 4, 37353-37358. https://doi.org/10.1039/C4RA05567E.

(45) Rioland, G.; Albrecht, S.; Josien, L.; Vidal, L.; Daou, T. J. The Influence of the Nature of Organosilane Surfactants and Their Concentration on the Formation of Hierarchical FAUType Zeolite Nanosheets. New J. Chem. 2015, 39, 2675-2681. https://doi.org/10.1039/C4NJ02137A.

(46) Itani, L.; Valtchev, V.; Patarin, J.; Rigolet, S.; Gao, F.; Baudin, G. Centimeter-Sized Zeolite Bodies of Intergrown Crystals: Preparation, Characterization and Study of Binder Evolution. Micropor. Mesopor. Mat. $\quad$ 2011, $138, \quad$ 157-166. https://doi.org/10.1016/j.micromeso.2010.09.011.

(47) Fawaz, E. G.; Salam, D. A.; Nouali, H.; Deroche, I.; Rigolet, S.; Lebeau, B.; Daou, T. J. Synthesis of Binderless ZK-4 Zeolite Microspheres at High Temperature. Molecules 2018, 23, 2647. https://doi.org/10.3390/molecules23102647.

(48) Tosheva, L.; Valtchev, V.; Sterte, J. Silicalite-1 Containing Microspheres Prepared Using Shape-Directing Macro-Templates. Micropor. Mesopor. Mat. 2000, 35-36, 621-629. https://doi.org/10.1016/S1387-1811(99)00256-5.

(49) Rioland, G.; Bullot, L.; Daou, T. J.; Simon-Masseron, A.; Chaplais, G.; Faye, D.; Fiani, E.; Patarin, J. Elaboration of FAU-Type Zeolite Beads with Good Mechanical Performances for Molecular Decontamination. RSC Adv. 2015, 6, 2470-2478. https://doi.org/10.1039/C5RA23258A. 
(50) Rioland, G.; Daou, T. J.; Faye, D.; Patarin, J. A New Generation of MFI-Type Zeolite Pellets with Very High Mechanical Performance for Space Decontamination. Micropor. Mesopor. Mat. 2016, 221, 167-174. https://doi.org/10.1016/j.micromeso.2015.09.040.

(51) Martin, T.; Galarneau, A.; Renzo, F. D.; Fajula, F.; Plee, D. Morphological Control of MCM-41 by Pseudomorphic Synthesis. Angew. Chem. Int. Ed. 2002, 41, 2590-2592. https://doi.org/10.1002/1521-3773(20020715)41:14<2590::AID-ANIE2590>3.0.CO;2-3.

(52) Martin, T.; Galarneau, A.; Di Renzo, F.; Brunel, D.; Fajula, F.; Heinisch, S.; Crétier, G.; Rocca, J.-L. Great Improvement of Chromatographic Performance Using MCM-41 Spheres as Stationary Phase in HPLC. Chem. Mater 2004, 16, 1725-1731. https://doi.org/10.1021/cm030443c.

(53) Petitto, C.; Galarneau, A.; Driole, M.-F.; Chiche, B.; Alonso, B.; Di Renzo, F.; Fajula, F. Synthesis of Discrete Micrometer-Sized Spherical Particles of MCM-48. Chem. Mater 2005, 17, 2120-2130. https://doi.org/10.1021/cm050068j.

(54) Galarneau, A.; Sachse, A.; Said, B.; Pelisson, C.-H.; Boscaro, P.; Brun, N.; Courtheoux, L.; Olivi-Tran, N.; Coasne, B.; Fajula, F. Hierarchical Porous Silica Monoliths: A Novel Class of Microreactors for Process Intensification in Catalysis and Adsorption. C. R. Chim 2016, 19, 231-247. https://doi.org/10.1016/j.crci.2015.05.017.

(55) Didi, Y.; Said, B.; Micolle, M.; Cacciaguerra, T.; Cot, D.; Geneste, A.; Fajula, F.; Galarneau, A. Nanocrystals FAU-X Monoliths as Highly Efficient Microreactors for Cesium Capture in Continuous Flow. Micropor. Mesopor. Mat. 2019, 285, 185-194. https://doi.org/10.1016/j.micromeso.2019.05.012.

(56) Said, B.; Grandjean, A.; Barre, Y.; Tancret, F.; Fajula, F.; Galarneau, A. LTA Zeolite Monoliths with Hierarchical Trimodal Porosity as Highly Efficient Microreactors for 
Strontium Capture in Continuous Flow. Micropor. Mesopor. Mat. 2016, 232, 39-52. https://doi.org/10.1016/j.micromeso.2016.05.036.

(57) Moukahhal, K.; Daou, T. J.; Josien, L.; Nouali, H.; Toufaily, J.; Hamieh, T.; Galarneau, A.; Lebeau, B. Hierarchical ZSM-5 Beads Composed of Zeolite Nanosheets Obtained by Pseudomorphic Transformation. Micropor. Mesopor. Mat. 2019, 288, 109565. https://doi.org/10.1016/j.micromeso.2019.109565.

(58) Nakanishi, K. Pore Structure Control of Silica Gels Based on Phase Separation. J. Porous Mater. 1997, 4, 67-112. https://doi.org/10.1023/A:1009627216939.

(59) Nakanishi, K.; Soga, N. Phase Separation in Silica Sol-Gel System Containing Polyacrylic Acid I. Gel Formation Behavior and Effect of Solvent Composition. J. Non-Cryst. Solids 1992, 139, 1-13. https://doi.org/10.1016/S0022-3093(05)80800-2.

(60) Babin, J.; Iapichella, J.; Lefèvre, B.; Biolley, C.; Bellat, J.-P.; Fajula, F.; Galarneau, A. MCM-41 Silica Monoliths with Independent Control of Meso- and Macroporosity. New J. Chem. 2007, 31, 1907. https://doi.org/10.1039/b711544j.

(61) Nakanishi, K.; Shikata, H.; Ishizuka, N.; Koheiya, N.; Soga, N. Tailoring Mesopores in Monolithic Macroporous Silica for HPLC. J. High Resolut. Chromatogr. 2000, 23, 106-110. https://doi.org/10.1002/(SICI)1521-4168(20000101)23:1<106::AID-JHRC106>3.0.CO;21.

(62) Galarneau, A.; Abid, Z.; Said, B.; Didi, Y.; Szymanska, K.; Jarzębski, A.; Tancret, F.; Hamaizi, H.; Bengueddach, A.; Di Renzo, F.; Fajula, F. Synthesis and Textural Characterization of Mesoporous and Meso-/Macroporous Silica Monoliths Obtained by Spinodal Decomposition. Inorganics 2016, 4, 9. https://doi.org/10.3390/inorganics4020009.

(63) Galarneau, A.; Iapichella, J.; Brunel, D.; Fajula, F.; Bayram-Hahn, Z.; Unger, K.; Puy, G.; Demesmay, C.; Rocca, J.-L. Spherical Ordered Mesoporous Silicas and Silica Monoliths as 
Stationary Phases for Liquid Chromatography. J. Sep. Sci. 2006, 29, 844-855. https://doi.org/10.1002/jssc.200500511.

(64) Landers, J.; Gor, G. Yu.; Neimark, A. V. Density Functional Theory Methods for Characterization of Porous Materials. Colloids Surf. A 2013, 437, 3-32. https://doi.org/10.1016/j.colsurfa.2013.01.007.

(65) Thommes, M.; Cychosz, K. A. Physical Adsorption Characterization of Nanoporous Materials: Progress and Challenges. Adsorption 2014, 20, 233-250. https://doi.org/10.1007/s10450-014-9606-z.

(66) Kabalan, I.; Lebeau, B.; Nouali, H.; Toufaily, J.; Hamieh, T.; Koubaissy, B.; Bellat, J.-P.; Daou, T. J. New Generation of Zeolite Materials for Environmental Applications. J. Phys. Chem. C 2016, 120, 2688-2697. https://doi.org/10.1021/acs.jpcc.5b10052.

(67) Ocampo, F.; Yun, H. S.; Pereira, M. M.; Tessonnier, J. P.; Louis, B. Design of MFI ZeoliteBased Composites with Hierarchical Pore Structure: A New Generation of Structured Catalysts. Cryst. Growth Des 2009, 9, 3721-3729. https://doi.org/10.1021/cg900425r.

(68) Schick, J.; Daou, T. J.; Caullet, P.; Paillaud, J.-L.; Patarin, J.; Mangold-Callarec, C. Surfactant-Modified MFI Nanosheets: A High Capacity Anion-Exchanger. Chem. Commun. 2011, 47, 902-904. https://doi.org/10.1039/C0CC03604H.

(69) El Hanache, L.; Sundermann, L.; Lebeau, B.; Toufaily, J.; Hamieh, T.; Daou, T. J. Surfactant-Modified MFI-Type Nanozeolites: Super-Adsorbents for Nitrate Removal from Contaminated Water. Micropor. Mesopor. Mat. 2019, 283, 1-13. https://doi.org/10.1016/j.micromeso.2019.03.049. 
Table of Contents Use Only

\section{Controlled crystallization of hierarchical monoliths}

\section{composed of nano-zeolites}

Kassem Moukahhal ${ }^{1,2,3}$, Nghia Huu Le $e^{1,2}$, Magali Bonne $e^{1,2}$, Joumana Toufaily3, Tayssir Hamieh ${ }^{3}$,

T. Jean Daou ${ }^{1,2 *}$ Bénédicte Lebeau ${ }^{1,2 *}$

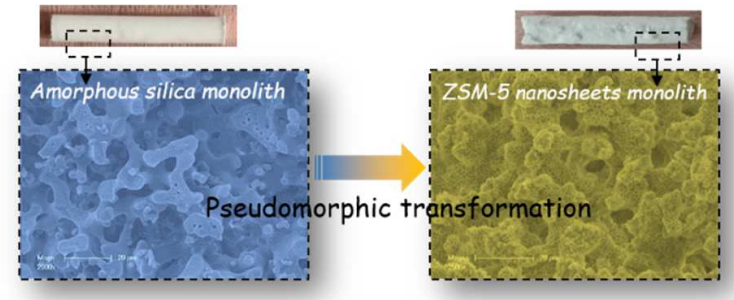

Guided crystallization of hierarchical monoliths composed of nanosheet ZSM-5 zeolites 